\title{
Life Cycle Energy and Carbon Assessment of Double Skin Façades for Office Refurbishments
}

\begin{abstract}
In countries like the UK, the upkeep of existing buildings is where the greatest opportunities for achieving carbon reduction targets lie. Façades are the physical barriers between outdoors and indoors, and their upgrade can arguably be amongst the most effective interventions to improve the existing stock. Double Skin Façades (DSFs) represent a possible solution for low-carbon refurbishment due to their capability to reduce energy consumption, and the related carbon emissions, of the building they are applied to. Although much research exists on maximising the operational energy savings of DSFs, little is known about their life cycle performance. This article addresses such a knowledge gap through a comparative life cycle assessment between DSF refurbishments and an up-to-standard, single-skin alternative. This study adopts a parametric approach where 128 DSF configurations have been analysed through primary data. Energy and carbon (both operational and embodied) are the units assessed in this research. Results show that DSFs are more energy-efficient than single-skin in $98 \%$ of the cases, and more carbon-efficient in $85 \%$ of the cases. Not only does this study represent the first broad parametric approach to evaluating life cycle energy and carbon of DSFs within its given context, but it also informs environmentally-aware design and application of DSFs.
\end{abstract}

Keywords: Double Skin Façade; Embodied Carbon; Embodied Energy; Global Warming Potential; Life Cycle Assessment; Low-Carbon Refurbishment.

\section{Introduction}

Buildings in the UK account for over $40 \%$ of national energy consumption and carbon dioxide emissions [1]. Due to poor thermal performance, mainly related to their age of construction, existing buildings offer a vast opportunity for decreasing those emissions and energy consumption [2]. Furthermore, only 1-2\% of the building stock is replaced each year [3], with 75\% of non-domestic buildings built before 1985 [4] and predictions that $75 \%$ - 90\% of them will still be in service by 2050 [5]. 
Offices are top contributors to energy consumption and carbon dioxide equivalent emissions $\left(\mathrm{CO}_{2 \mathrm{e}}\right)$ in the non-domestic sector [6], and reducing energy demand through retrofitting deserves to become a priority [7]. Nevertheless, existing buildings remain largely untouched, and many refurbishments fail to deliver low-carbon buildings [8, 9] despite estimates which suggest innovations in non-domestic buildings can offer savings of up to $86 \mathrm{MtCO}_{2}$ by 2050 [10]. Therefore, one of the major challenges for the future is "to promote the sustainable refurbishment of that consolidated [building] stock” [11].

In this respect, improvements to the building façade are arguably one of the most effective interventions. Façades provide physical barriers between outdoor and indoor spaces, thus playing a major role in energy consumption [12] and, consequently, in carbon dioxide emissions, which has been proven to be more valid in refurbishment projects [5]. Glazed Double Skin Façades (DSFs) have been identified as a suitable demand-side technology to reduce energy consumption and GHGemissions [13], whilst providing comfortable conditions to the occupied spaces [14]. In refurbishments a DSF consists of a second, glazed skin installed in front of the existing building façade which creates an air space that acts as a thermal buffer, a ventilation channel, or a combination of both. The operational behaviour of DSFs has been widely studied and in temperate climates this technology seems capable of noteworthy reductions in the energy demand of the building they are applied to [12, 1517]. Conversely there are also studies reporting increased energy consumption directly linked to the DSF $[18,19]$, which highlight the need for careful analysis at the design stage. To avoid the overheating of the upper floors Hamza et al. [20] showed the need to extend the cavity above the roof level to provide enough thermal stack. Pasquay [21] monitored existing buildings in Germany concluding that natural 
ventilation with the DSF is possible all year round. Artmann et al. [22] showed the need of operable inlets and outlets of the cavity to maximise natural ventilation whilst preserving the thermal buffer potential.

The wealth of studies on the operational phase of the DSF are starkly contrasted by an extremely limited knowledge about its embodied energy and carbon.

This paper aims to address such a knowledge gap through a comparative assessment of DSF and an up-to-standards single-skin refurbishment alternative. The life cycle environmental impacts of DSFs for office refurbishments are assessed through a cradle-to-grave LCA with a twofold aim. Firstly, the life cycle energy is assessed through the comparison of operational energy savings of DSFs over a singleskin solution against DSFs embodied energy figures to establish whether, and in which cases, the former outweighs the latter. Secondly, the same comparative assessment is then made from a carbon perspective, in terms of $\mathrm{CO}_{2 \mathrm{e}}$ emissions; to determine if DSFs can be considered as a low-carbon technology for the refurbishment of the existing office stock in Britain.

\section{Life Cycle Assessment of Double Skin Façades}

Sustainability assessment of buildings throughout their whole life cycle is not currently regulated by policy in Europe [23], although there exists standards that address LCA in general $[24,25]$, and the sustainability of construction works in particular [26, 27]. Nevertheless, LCA scenarios are inconsistent and varying with regards to settings, approaches and findings. Such issues hinder consolidation and comparison of results. Different lifetime figures, lack of parametric approaches addressing multiple scenarios, little clarity in the functional unit (FU) considered, diverse methodologies and methods for conducting the studies, and the focus mainly on real buildings - which makes any generalisation hard to make - are the most 
important reasons [28]. Such diversity is justified by and originates from the inherent complexity of the construction sector where each material used has its own specific life cycle and all interact dynamically in both temporal and spatial variations [29-31]. The long lifespan of buildings combined with change of use during their service life also imply lower predictability and higher uncertainty of variables, parameters, and future scenarios [31, 32].

Only few studies exist that provide a detailed analysis on DSFs from a life cycle perspective [33, 34]. This on its own represents a significant knowledge gap considering that the DSF is a technology widely used in the Architecture, Engineering, and Construction (AEC) industry. Existing studies are mainly located in specific contexts, thus increasing the difficulty in comparing and replicating results and methodologies. They also refer to very particular and innovative DSF configurations which do not represent the current practice in the AEC industry.

Wadel et al. [33] adopt a simplified LCA for an innovative type of DSF with vertical shading devices placed at specific intervals. The use phase is not incorporated in the LCA and impacts assessed throughout the study are the $\mathrm{EE}$ and $\mathrm{CO}_{2}$ emissions, the FU being $1 \mathrm{~m}^{2}$ of façade with a lifespan of 50 years. With reference to those two impact categories the DSF, in its best configuration, is capable of a $50 \%$ reduction in energy consumption and $\mathrm{CO}_{2}$ emissions compared to conventional façades [33].

de Gracia et al. [34] conduct a cradle-to-grave LCA of a DSF with phase change materials (PCM) in its cavity. Their LCA utilises the Eco-Indicator 99 (EI99) [35], an impact assessment method based on endpoints. This means that results from different impact categories are normalised and brought together to contribute to a final, single, cumulative score (known as an 'endpoint') for the product/process under examination [35]. The FUs used are two whole cubicles constructed in Spain, one 
with a DSF and the other without, assuming a lifespan of 50 years where the DSF appears to reduce the environmental impacts by $7.5 \%$ compared to the reference case [34].

Notwithstanding the importance of regional and local foci in LCA, neither of the studies allow for generalisations needed for better informed applications of DSFs. More generic perspectives would enable a broader use of the methods and also ease comparison of results from different contexts. A less context-specific environmental impact assessment of office façades has been conducted by Kolokotroni et al. [36]. They assessed one specific DSF configuration among many options for both naturally-ventilated and air-conditioned offices. As such the depth of the investigation is forfeited for the breadth. The authors assessed EE in their study and also environmental impacts through the EI99 method [35], finding the DSF has high EE and low EI99 score for both naturally ventilated and air-conditioned offices [36].

Apart from these three studies DSFs have not been investigated from a life cycle perspective. Nor have they been studied in a refurbishment context in comparison with single-skin solutions. Consequently, primary data related to DSFs' EE are still largely missing in the literature. This is mainly due to lack of information for glass-related processes, and echoes a known issue in the LCA community: the lack of reliable and complete data about buildings materials and assemblies [37-39] which, if existed, would allow for better informed environmentally-conscious decisions.

\section{Research Design}

This article focuses on a comparative assessment between double- and singleskin strategies for office refurbishments in the UK, to answer the following two research questions: 
1. From a life cycle perspective, are DSFs more energy efficient than upto-standards single-skin alternatives for office refurbishments in the UK?

2. From a life cycle perspective, are DSFs more carbon efficient than upto-standards single-skin alternatives for office refurbishments in the $\mathrm{UK}$ ?

To answer those questions, a cradle-to-grave LCA of DSFs for office refurbishment has been conducted based on the aforementioned existing standards [24-27]. The LCA methodological framework consists of four phases [24]: (1) goal and scope definition, (2) life-cycle inventory analysis (LCI), (3) life-cycle impact assessment (LCIA), and (4) interpretation.

The first phase deals with defining the goal and scope of study; which has been given in the introduction of the paper. It also addresses system boundary, functional unit to ensure comparability and reproducibility, level of detail, and depth and breadth of the assessment. In this stage, questions and/or hypotheses are generally formulated. For the assessment, this research uses the attributional approach, which focuses on physical flows to and from a life-cycle and its components, this being the approach recommended by national documents to assess GHG-emissions of goods and services [40].

LCA literature provides case studies which are often based on specific buildings, thus hindering generalisation of the conclusions and comparability of the results. Therefore, a generic yet representative office with a very slender built form has been selected, this being the most common office building type in England [41, 42]. It consists of 9 floors of $66.6 \mathrm{~m} \times 16 \mathrm{~m}$ with an open plan layout, totalling 9590 $\mathrm{m}^{2}$ of treated floor area (TFA). Window to wall ratio (WWR) equals to 0.25 which is 
a highly correlated value to offices of this type [43]. Such built forms represent the vast majority of non-domestic buildings in the UK [42] and are typical of large buildings constructed between the 1960s and 1990s; this implies two important features in terms of its representativeness:

1. Most of the office floor spaces, in all regions of the UK, were built before $1990[44]$

2. Buildings in that age band are those most frequently encountered in nondomestic refurbishments in the UK [8].

The vast majority of existing UK offices are in fact naturally ventilated and do not include mechanical cooling systems of any sort [8], since these would require a terrific effort to be installed. When cooling is installed in existing offices, it ends up accounting for more than $30 \%$ of the total building-related $\mathrm{CO}_{2}$ emissions [45]. There are also clear recommendations to prefer, wherever possible, natural ventilation strategies over mechanical systems with the aim to reduce the building's energy demands and $\mathrm{CO}_{2 \mathrm{e}}$ emissions [8]. Finally, national reports indicate a very low significance of cooling loads, with values as little as 5\% [8]. For all the above reasons the building model for this study is naturally ventilated.

Figure 1 shows an axonometric view of the building superimposed on a site in London and a detailed axonometric view of the functional unit which, in terms of area, consists of $5.25 \mathrm{~m}^{2}$ of DSF. The façade service life is assumed to be 25 years in line with recent studies specifically focused on building façades in the UK [46] . After such time, the end of life has been modelled using the waste/recycling scenario for England available in the Ecoinvent 3 database based on figures from DEFRA [47]. 

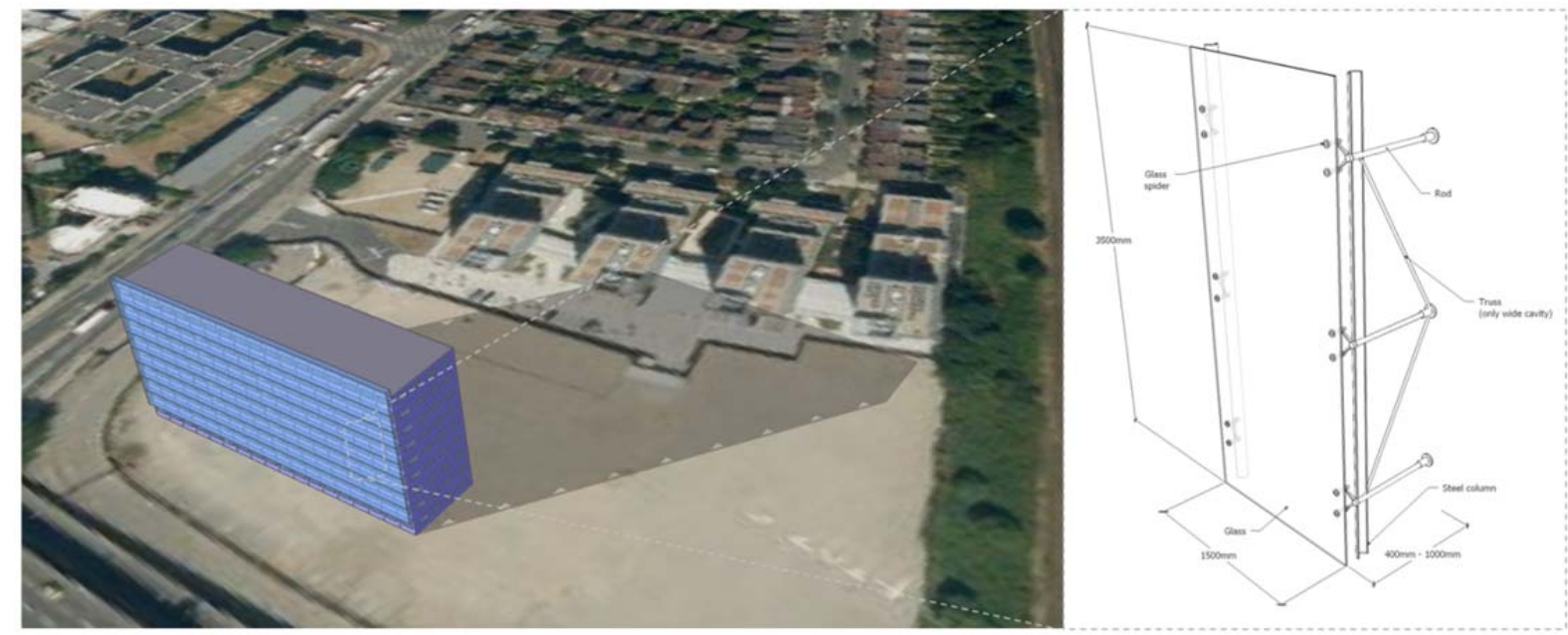

Figure 1 - Axonometric views of the building (Map data: Google, DigitalGlobe) and the functional unit

The second phase, or LCI, includes a detailed inventory of inputs/outputs and the necessary data collection to fulfil the goal of the LCA. In terms of the data collection approach, three methods are found in built environment studies: the process analysis, the input-output analysis, and the hybrid analysis [48]. A process-based analysis refers to a mix of processes, products, and location-specific data to calculate and establish the environmental impact of a product system, and in the LCAs of buildings and their components it appears to be the most reasonable and detailed choice for in-depth studies [26, 27, 49]. SimaPro is the software tool used for the third phase, LCIA, where the significance of environmental impacts is quantified using the results from the LCI stage. Two different calculation methods have been used: the CED [50] for the embodied energy, and the GWP over a 100-year horizon [51] (also known as IPCC 2013 GWP 100a) for the embodied carbon.

In the present work, a clear distinction is considered between the occupied phase of the building, i.e. the operational stage, and pre-occupancy and end-of-life phases. For the operational phase, dynamic thermal modelling of the building [52, 53] has been deployed to determine energy figures for the DSF configurations and compare them against a single-skin alternative. This approach has already been used 
in new buildings to explore the performance of various DSF configurations against a base case [12]. The location of the building is London, which is characterised by a temperate climate, with warm summers, and without a dry season (code in the Köppen-Geiger climate classification: Cfb) [54]. A characterisation of the climate can be found in Figure 2, Figure 3, and Figure 4.

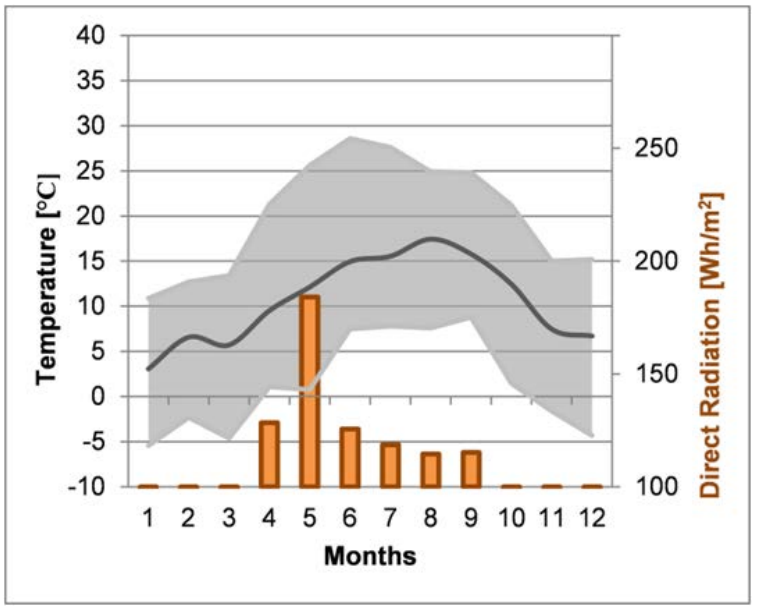

Figure 2 - Monthly temperature and solar radiation values for London

Figure 2 shows the maximum, minimum, and average monthly temperature, and the maximum values of the direct solar radiation.

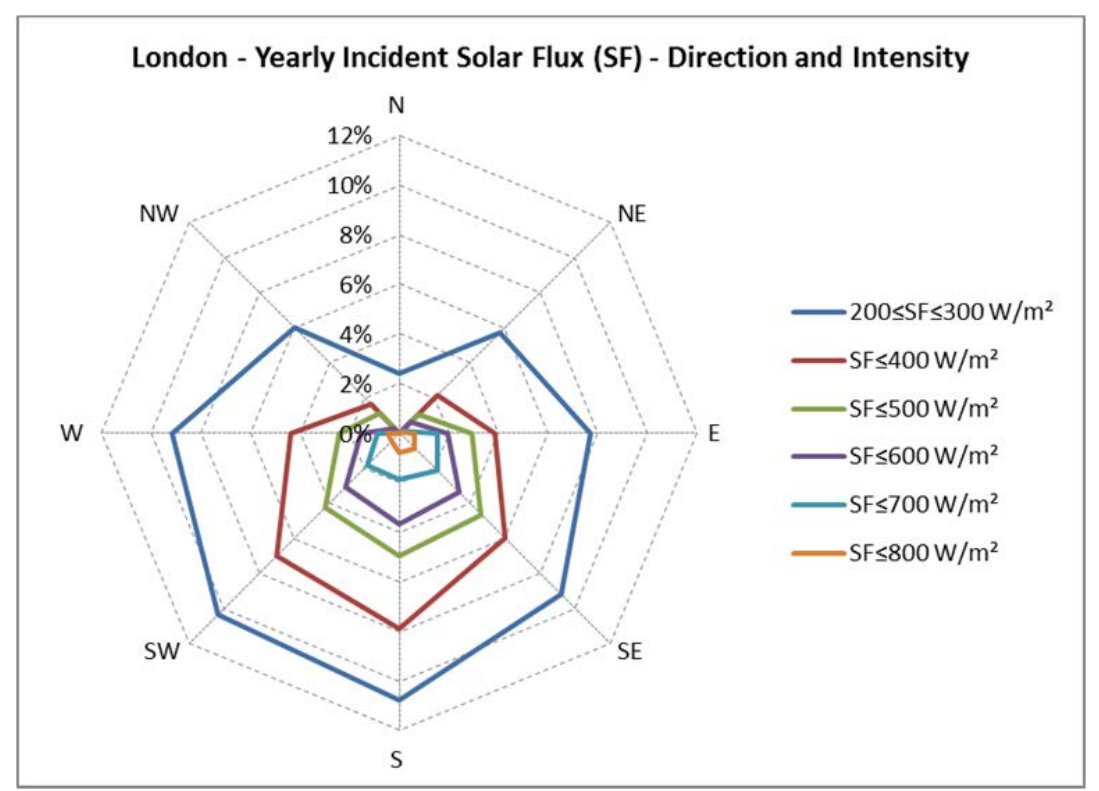

Figure 3 - Intensity and direction of solar flux values exceeding $200 \mathrm{~W} / \mathrm{m}^{2}$ in London 
Figure 3 shows the direction and intensity of the solar flux throughout the year. In London, the solar flux is lower than $200 \mathrm{~W} / \mathrm{m}^{2}$ for most of the year and, therefore, only values exceeding that threshold have been plotted. Figure 4 shows the wind rose, with prevailing wind speed and direction.

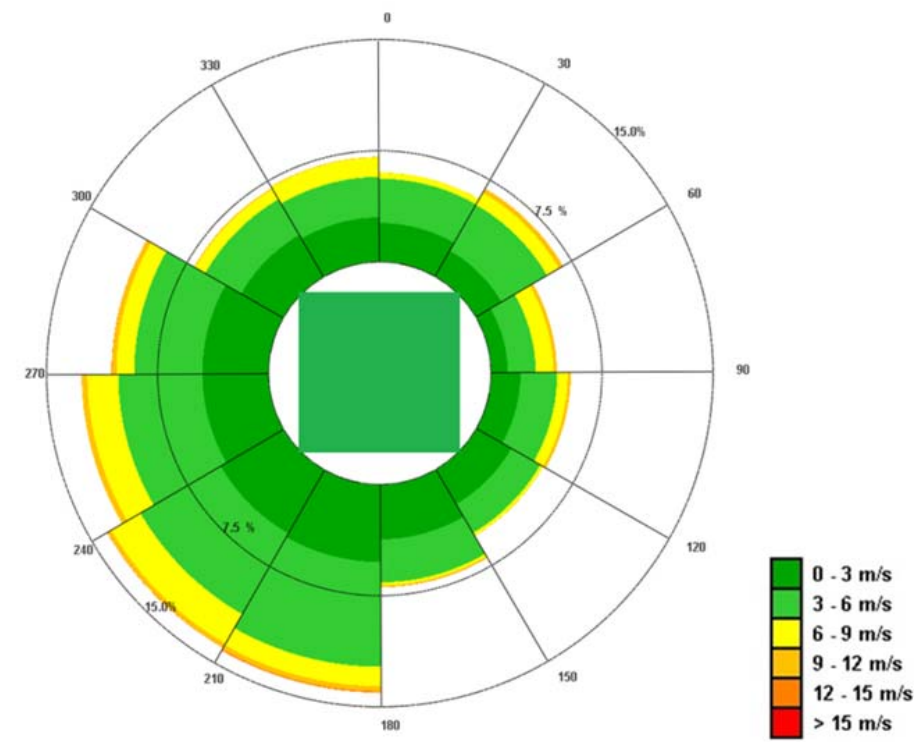

Figure 4 - Wind rose for London

For all life cycle phases other than operational, consultations with manufacturers and façade engineers helped map out the life cycle processes (LCPs) related to the use of DSF in refurbishment. Relevant primary data have also been collected from European manufacturers. A framework to help through the process mapping and the subsequent data collection has been adapted from existing standards [27], with an aim to identify elementary LCPs related to the use of DSFs in office refurbishments (Figure 4). An elementary LCP is here defined as a process that can be constituted of several activities as long as they all happen within the same manufacturing plant. If a firm needs to outsource a manufacturing activity on its products, this becomes another elementary LCP and the two are linked by transportation (both back and forth if products then return to the original plant). 'Vertical' supply chain oriented approaches generally focus on one process at time, 
tracing upstream the processes that feed into, and downstream the processes fed by the one under consideration. The framework in Figure 4 differs from those built around an upstream/downstream supply chain oriented view, and may help reduce the risk of double counting (especially transportation figures), since it follows the actual consequentiality of events and it switches the focus to a before/after horizontal view.

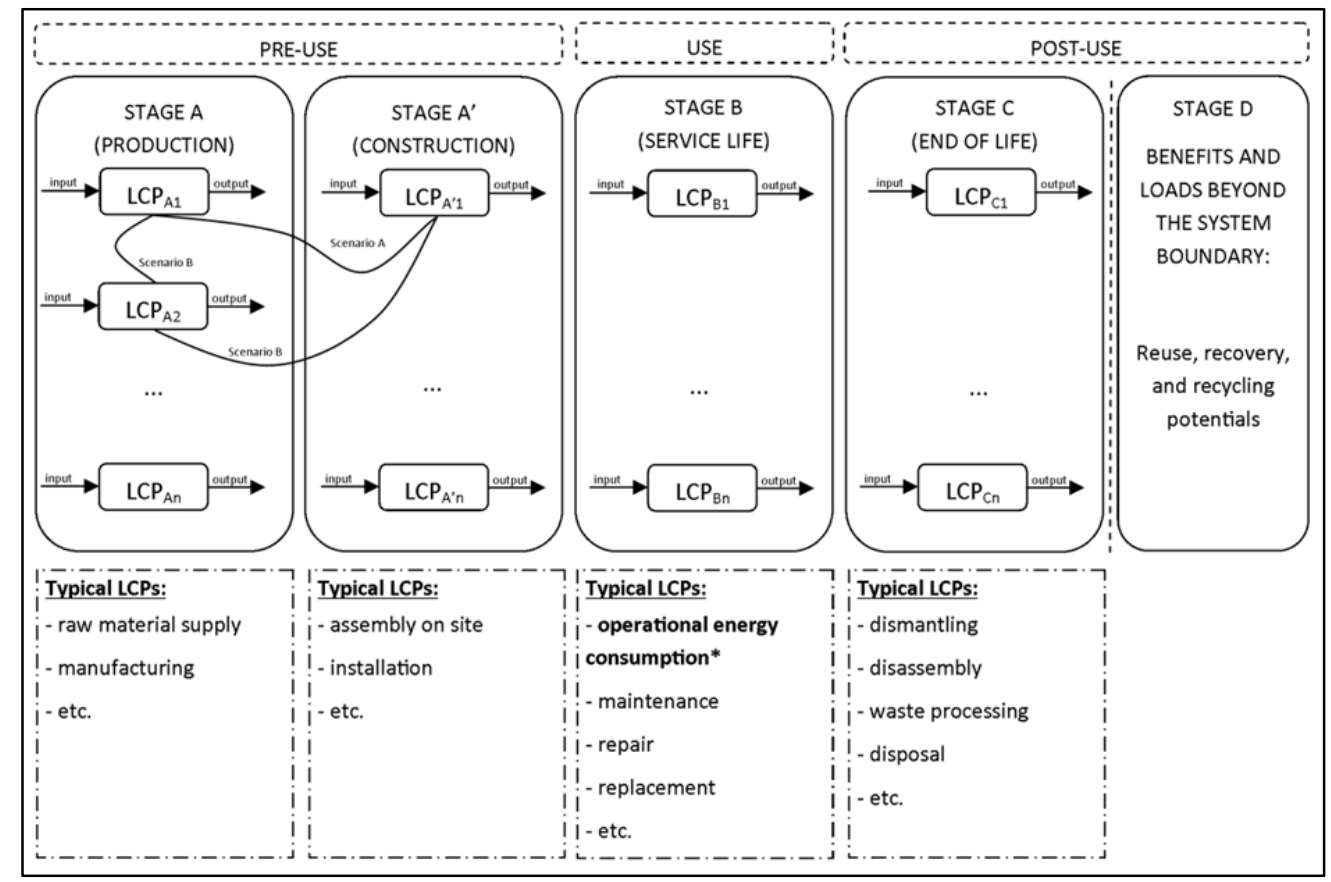

Figure 5 - Framework used for process mapping and data collection adapted from BN EN 15643-2:2011

[23][55][39][55][47][25, 26, 48][25, 26][49][50]Once EE and EC figures are assessed for all the elementary LCPs through the calculation methods introduced above, the whole life EE and EC can be computed by means of Equation (1) and Equation (2):

$$
\begin{aligned}
& W L E E=\sum_{i=A}^{D} \sum_{j=1}^{n} E E\left(E L C P_{i j}\right)+\sum_{i=A}^{D} \sum_{j=1}^{n} E E\left(T_{i j}\right) \\
& W L E C=\sum_{i=A}^{D} \sum_{j=1}^{n} E C\left(E L C P_{i j}\right)+\sum_{i=A}^{D} \sum_{j=1}^{n} E C\left(T_{i j}\right)
\end{aligned}
$$

where: 
- $\quad E E(E L C P i j) ~[E C(E L C P i j)]$ is the embodied energy [embodied carbon] related to all the activities of the specific elementary life cycle process (ELCP) 'j' of the stage 'i';

- $\mathrm{EE}(\mathrm{Tij})[\mathrm{EC}(\mathrm{Tij})]$ is the embodied energy [embodied carbon] related to transportation from the specific elementary life-cycle process ' $\mathrm{j}$ ' of the stage ' $\mathrm{i}$ ' to whichever is the destination.

Once whole-life embodied energy and carbon have been determined they can be compared against the service-life operational energy and carbon balance, intended as the difference between the use of DSFs over single-skin in the operational stage.

In this study, common elements shared between the two, i.e. single- and double-skin refurbishments, are excluded, and the system boundaries for the FU are drawn around additional elements, (sub)assemblies, processes, and stages that a DSF strategy would bear (Figure 6).[56] 


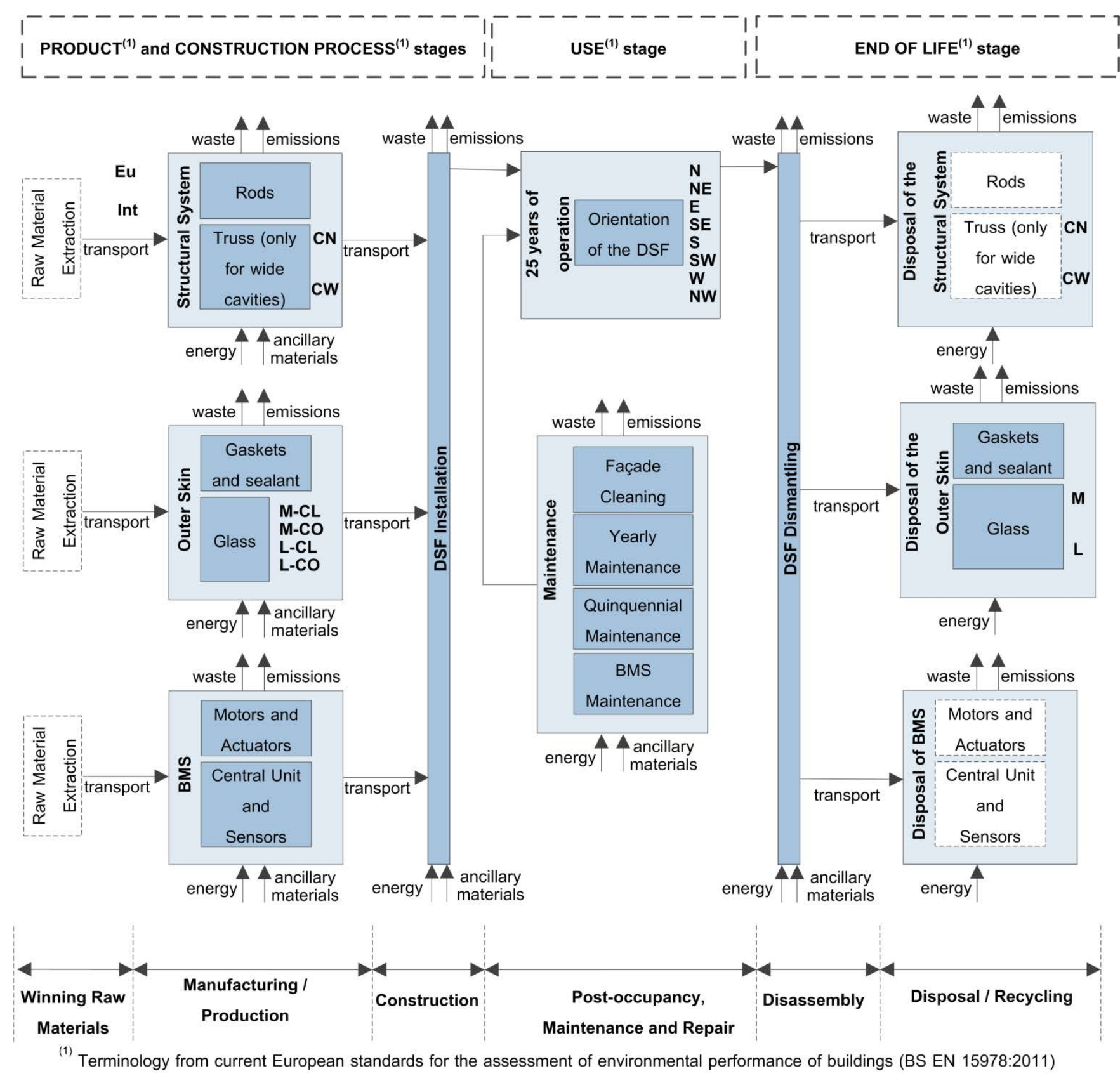

Figure 6 - Flowchart for the functional unit and its system boundaries (codes used are defined in Table 2) - dashed assemblies are those for which solely the EcoInvent database has been used

This assumption is based on national standards about DSF and building regulations for refurbishments. British standards [55] define a double skin façade as a “curtain wall construction comprising an outer skin of glass and an inner wall constructed as a curtain wall that together with the outer skin provide the full function of a wall”. In the case of this research, the DSF opens dynamically according to the weather and the cavity thermal conditions and frequently features open inlets and 
outlets for the air to flow. Such an operational behaviour means that there are several instances in a year in which the sole inner skin has to 'provide the full function of a wall' [55]. For this reason it is assumed that the inner skin of the DSF matches the same specification required for the single-refurbishment in the current building regulations [56].

For instance, the replacement of old, single-glazing and metal frame with upto-standard, double-glazing units (DGU) mounted on thermal-break frames, would be exactly the same in both cases, thus representing a quantity that just numerically shifts the results without adding anything to the study. Figure 8 shows a detailed cross section of the two alternatives side by side, where it can be seen that the single skin and the inner skin of the DSF are identical.

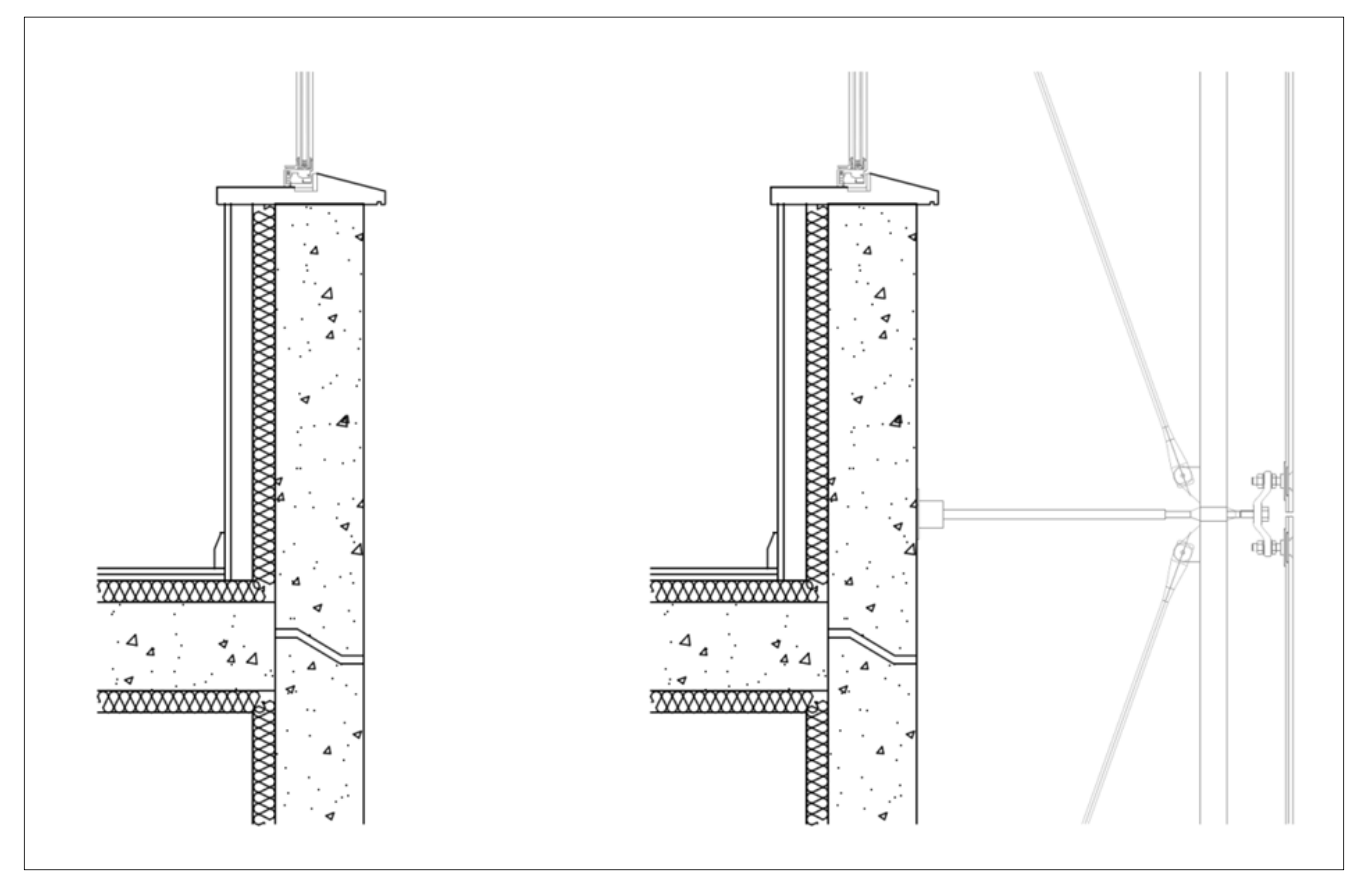

Figure 7 - Detailed cross section of the single skin (left) and double skin (right) refurbishment alternatives

Table 1 shows the heat transfer coefficients of the thermal elements of the building fabric which are the recommended improved values in the building regulations [56]. 
Table 1 - Heat transfer coefficient for elements of the building fabric and details of the dynamic simulation

\begin{tabular}{|c|c|c|c|}
\hline Element of the & Corresponding & Heating \& occupancy profile & ASHRAE 8am-6pm M-F \\
\hline \multirow{2}{*}{ building fabric } & \multirow{2}{*}{ U-value } & Heating set point/system & $19.5^{\circ} \mathrm{C} /$ radiators \\
\hline & & Internal gains & $21.5 \mathrm{~W} / \mathrm{m}^{2}$ \\
\hline Roof & $0.18 \mathrm{~W} / \mathrm{m}^{2} \mathrm{~K}$ & Max sensible people gain & $73.2 \mathrm{~W} /$ person \\
\hline Ground floor & $0.22 \mathrm{~W} / \mathrm{m}^{2} \mathrm{~K}$ & Occupancy density & $13.93 \mathrm{~m}^{2} /$ person \\
\hline External walls & $0.26 \mathrm{~W} / \mathrm{m}^{2} \mathrm{~K}$ & Infiltration max flowrate & 0.4 ach \\
\hline External windows & $1.60 \mathrm{~W} / \mathrm{m}^{2} \mathrm{~K}$ & External windows open at & $22{ }^{\circ} \mathrm{C}$ \\
\hline DSF glazing & $4.62 \mathrm{~W} / \mathrm{m}^{2} \mathrm{~K}$ & Cavity opens at & $15^{\circ} \mathrm{C}$ or $20^{\circ} \mathrm{C}$ out. temp \\
\hline
\end{tabular}
$[40,41][42][45]$

The DSF structural system is made of stainless steel, with columns, rods, trusses, and spider joints connecting to the external glazed skin. Several DSF geometries exist; the configuration chosen here is multi-story, consisting of a cavity with no horizontal or vertical partitions. The cavity is equipped with a basic form of Building Management System (BMS) which opens the bottom and top of the cavity when the outside air wet-bulb temperature exceeds $20^{\circ} \mathrm{C}$ or the cavity air temperature exceeds $15^{\circ} \mathrm{C}$ (from here on both are referred to as opening thresholds). Regarding cavity width, narrow and wide categories are widely acknowledged and therefore are both considered. Trusses are only necessary for the wide cavity; hence they are not part of the FU for the narrow scenarios. Glass composition and coating, structure manufacture, and building orientation are all additional parameters which have been considered due to the input received during the consultations with façade firms and engineers to ensure this research would be representative of current practice (Table 2). Some combinations are more common than others; for instance: a DSF is unlikely to be installed on a north-facing façade due to the little solar radiation it would receive. However, for the same reason a north-facing façade is often the coldest part of the building and the thermal buffer created by the DSF could contribute significantly to the reduction of the heating loads. In order to postpone such decisions down the line, 
i.e. after the execution of this research, a full factorial design approach was chosen and all possible permutations of the parameters considered have been assessed.

Table 2 - Codes and details of the options assessed

\begin{tabular}{|c|c|c|c|c|}
\hline Parameter & Options assessed & Code(s) & No. & Details \\
\hline \multirow[t]{2}{*}{ Cavity } & Narrow & $\mathrm{CN}$ & 2 & 400 mm wide \\
\hline & Wide & $\mathrm{CW}$ & & $1000 \mathrm{~mm}$ wide \\
\hline \multirow[t]{2}{*}{$\begin{array}{l}\text { Glass } \\
\text { composition }\end{array}$} & Monolithic & $\mathrm{M}$ & 2 & $\begin{array}{l}12 \mathrm{~mm} \text { thermally toughened (TT) - Heat } \\
\text { Soak Tested (HST) }\end{array}$ \\
\hline & Laminated & $\mathrm{L}$ & & $8 \mathrm{~mm} \mathrm{TT}+8 \mathrm{~mm} \mathrm{TT}+1.52 \mathrm{~mm} \mathrm{PVB}$ \\
\hline \multirow[t]{2}{*}{ Glass coating } & Clear & CL & 2 & Clear Float Glass \\
\hline & Coated & $\mathrm{CO}$ & & Solar Control Glass \\
\hline Structure & Central Europe & $\mathrm{Eu}$ & 2 & Lorry Euro $4(500 \mathrm{~km})$ \\
\hline Manufacture* & China & Int & & $\begin{array}{l}\text { Transoceanic ship }(20070 \mathrm{~km}) \text { - Train } \\
(140 \mathrm{~km}) \text { - Lorry Euro } 4(120 \mathrm{~km})\end{array}$ \\
\hline Orientation & $\begin{array}{l}\text { Incremental steps of } \\
45^{\circ}\end{array}$ & $\begin{array}{l}\text { E, NE, N, NW, } \\
\text { W, SW, S, SE }\end{array}$ & 8 & \\
\hline
\end{tabular}

*=Due to the lack of reliable data this parameter only involves the difference in terms of transportation.

In addition to the 128 combinations of Table 2, eight single-skin options (one for each orientation) were also realised and assessed in order to allow OE comparisons.

Data collection for this research has been approached in a systematic way through the mapping of life cycle processes (LCPs) related to DSF refurbishments. LCPs have been screened against the Ecoinvent database [47] and leading UK-based database [57], highlighting significant missing data. Primary data were collected for most of the life cycle processes, assemblies and subassemblies. This can be seen from Figure 6 where only the elements within dashed boxes are entirely assessed through EcoInvent data. To fill the substantial gap in available data in this area, companies have been contacted for data collection by means of preliminary interviews which were then followed by site visits and in-depth field study to enhance the reliability and validity of this study. In total, seven companies contributed to data for this research, divided as follows: 
- One façade engineering firm, which contributed to the definition and specification of the functional unit, the operational setting of the DSF, and the recommended maintenance schedule;

- One façade construction firm, which contributed to the quantification of all the details of the functional unit, the source of materials, the processes necessary for installation, maintenance and dismantling of the DSF, and the end-of-life scenarios for the materials;

- Five manufacturing companies operating in the flat glass business for the construction industry, which contributed to all glass-related processes, outer skin cleaning and maintenance activities, and glass disposal scenarios. In total, data for over 200 glass panes have been collected by the author throughout the whole production process in terms of inputs, outputs, energy, ancillary materials, and waste.

\section{Results and Discussion}

\subsection{Operational Energy}

Figure 8a and Figure 8b show the operational energy results, in the form of yearly space heating for all the 64 configurations considered, for narrow and wide cavities respectively, (source of materials does not influence this figure, hence the number is half of the total 128 options). 


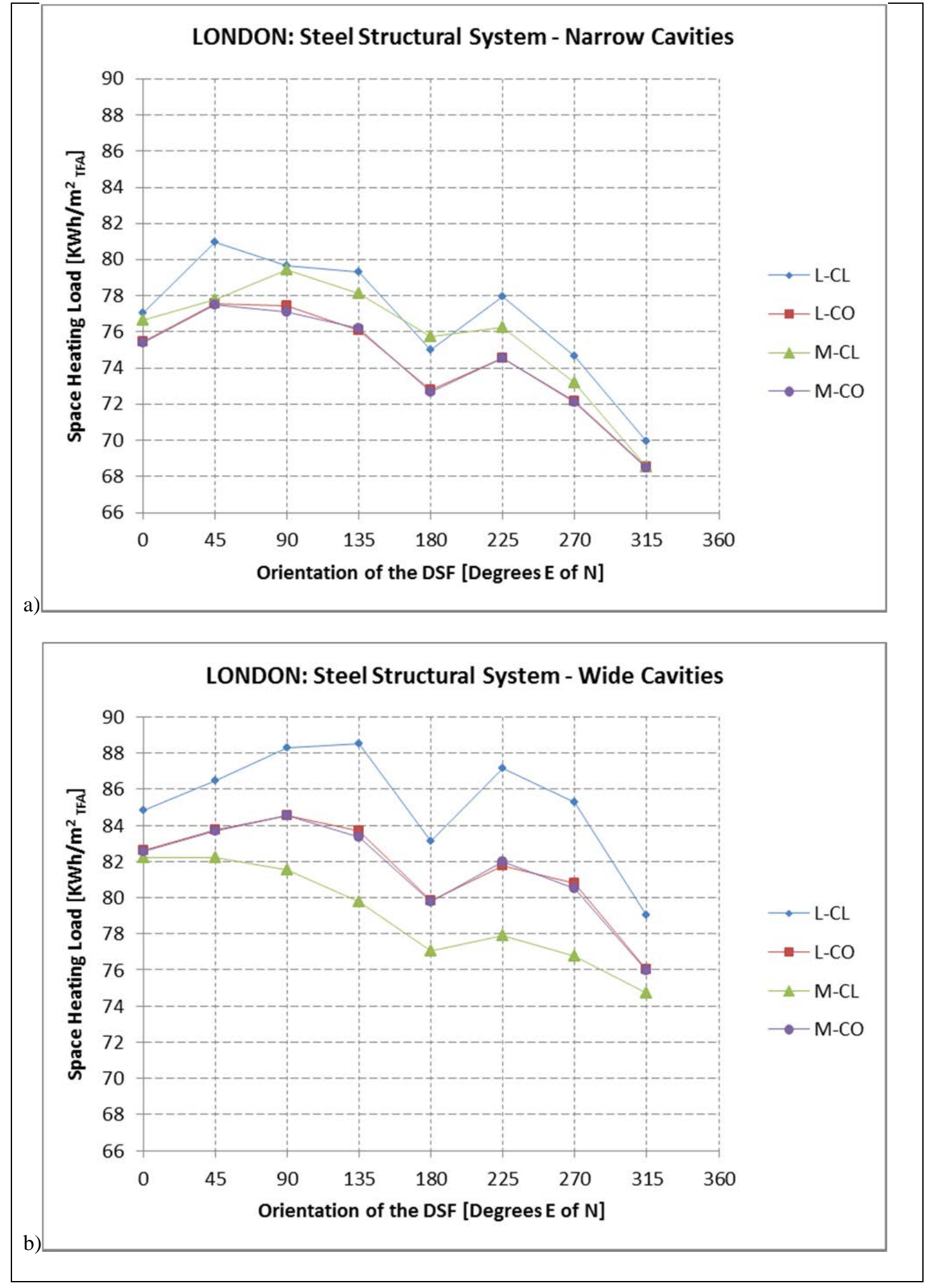

Figure 8 - Operational Energy in terms of Yearly specific space heating load for all 64 relevant configurations ( $\mathrm{L}=$ laminated glass; $\mathrm{M}=$ monolithic glass; $\mathrm{CL}=$ clear glass; $\mathrm{CO}=$ coated glass)

Heating energy figures, although varied due to the high number of scenarios assessed, compare well with existing benchmarks for UK offices [59, 60]. Figure 8 
also shows that narrow cavities have a more positive effect on the building they are applied to, by resulting in a lower space heating load. This is explained as wider cavities imply a higher mass of air (2.5 times $-100 \mathrm{~cm}$ vs. $40 \mathrm{~cm}$ width as shown in Table 2) that needs to be solar-heated prior to 'activating' the thermal buffer function of the DSF.

Additionally, in both Figures 8a and 8b two minima can be identified, i.e. for a South and North-West orientation. For the former, the reason is to be found in the higher solar flux (Figure 3) which emphasises the thermal buffer potential of the DSF; however, due to the south orientation the air temperature in the cavity reaches the opening threshold and the DSF therefore intermittently acts as a buffer and a solar chimney. Figure 9 shows a diagram of the building physics of the open cavity for a South oriented model and helps explain this behaviour. For the North-west case, the far lower solar flux received impedes the internal temperature in reaching the opening threshold of the cavity and the DSF acts as a thermal buffer for most of the cold season, thus minimising the space heating demand. Figure 8 also shows that the choice of the glass has more influence on wide cavities than on the narrow ones. This is due to the considerably lower volume, and therefore mass of air that narrow cavities imply; making trade-offs less evident when compared to wider cavities. The lower mass of air in narrow cavities needs less time to reach the temperature thresholds that open and close the inlets and outlets and, therefore, it works intermittently more frequently which reduces the influence of glass coating and composition. 


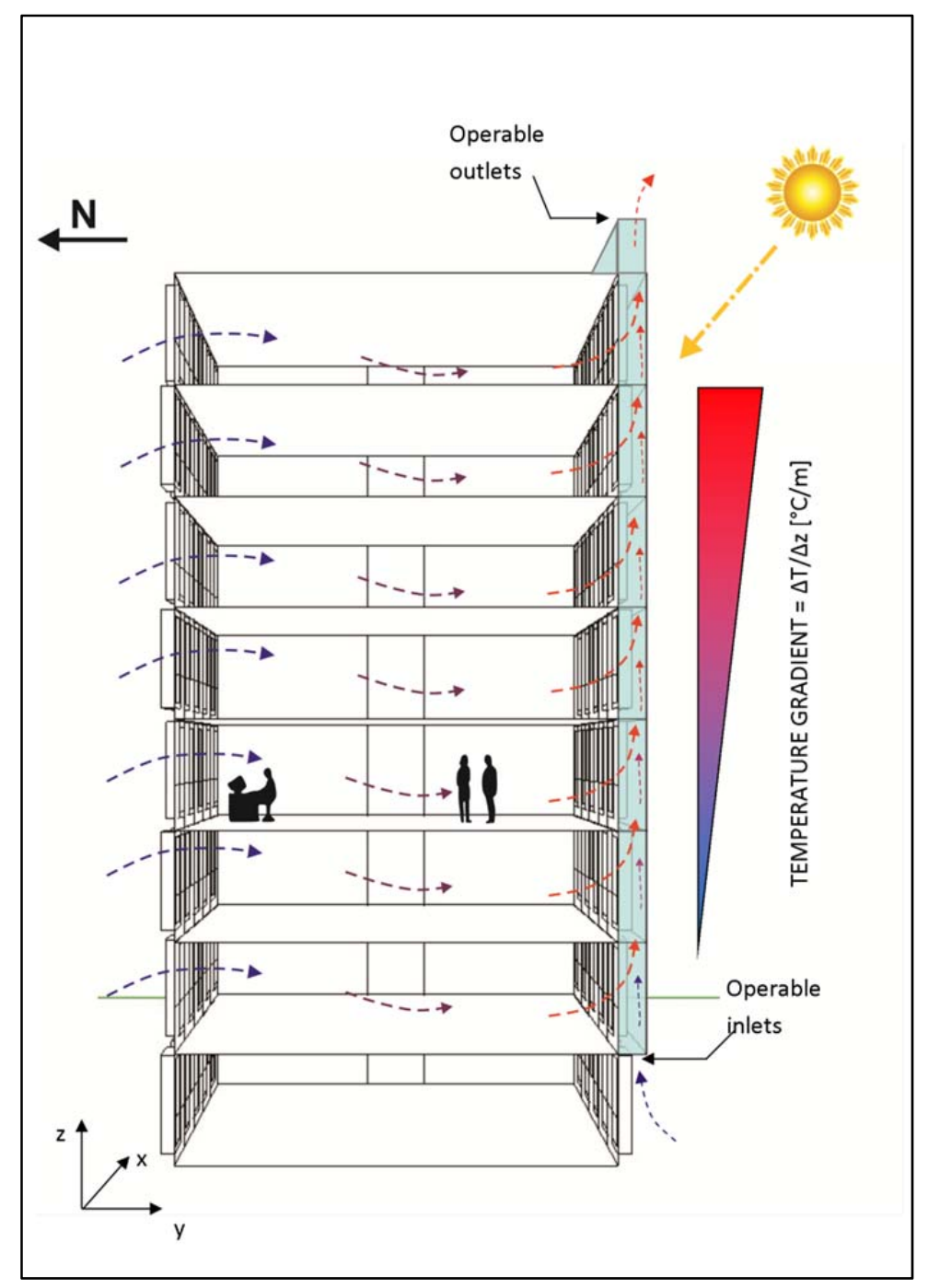

Figure 9 - Diagram of the building physics for a South oriented model

\subsection{Embodied Energy and Embodied Carbon}

This section presents results on embodied energy and carbon with a specific focus on the contributions that different life cycle stages and assemblies have towards the final figures. The terminology of life cycle stages and assemblies is the same as presented in Table 2 and in the flowchart in Figure 6.

Figure 10 demonstrates that glass and steel are major contributors to the whole life energy. Although this could be somewhat expected it is worth remembering that a significant amount of primary data related to glass and installation processes were collected from manufacturers due to unavailability in existing databases. Failure to do 
so would have resulted in a significantly smaller impact for the glass macro assembly. Glass data proved particularly significant; glass edging is the process with the highest embodied carbon. If the other glass processes are normalised and compared to it, heat soak testing, glass cutting, and washing have values of $86 \%, 59.5 \%$, and $11.6 \%$ respectively. Tempering, which was the only process available in the Ecoinvent database, only contributes to $27.3 \%$ of the total impact of the glass related processes. As such, $72.7 \%$ of the glass-manufacturing related impacts would have been neglected. This aspect reinforces the need for a concerted effort to increase the amount of primary data available on embodied energy and carbon in the construction sector if more realistic whole life figures are to be obtained.

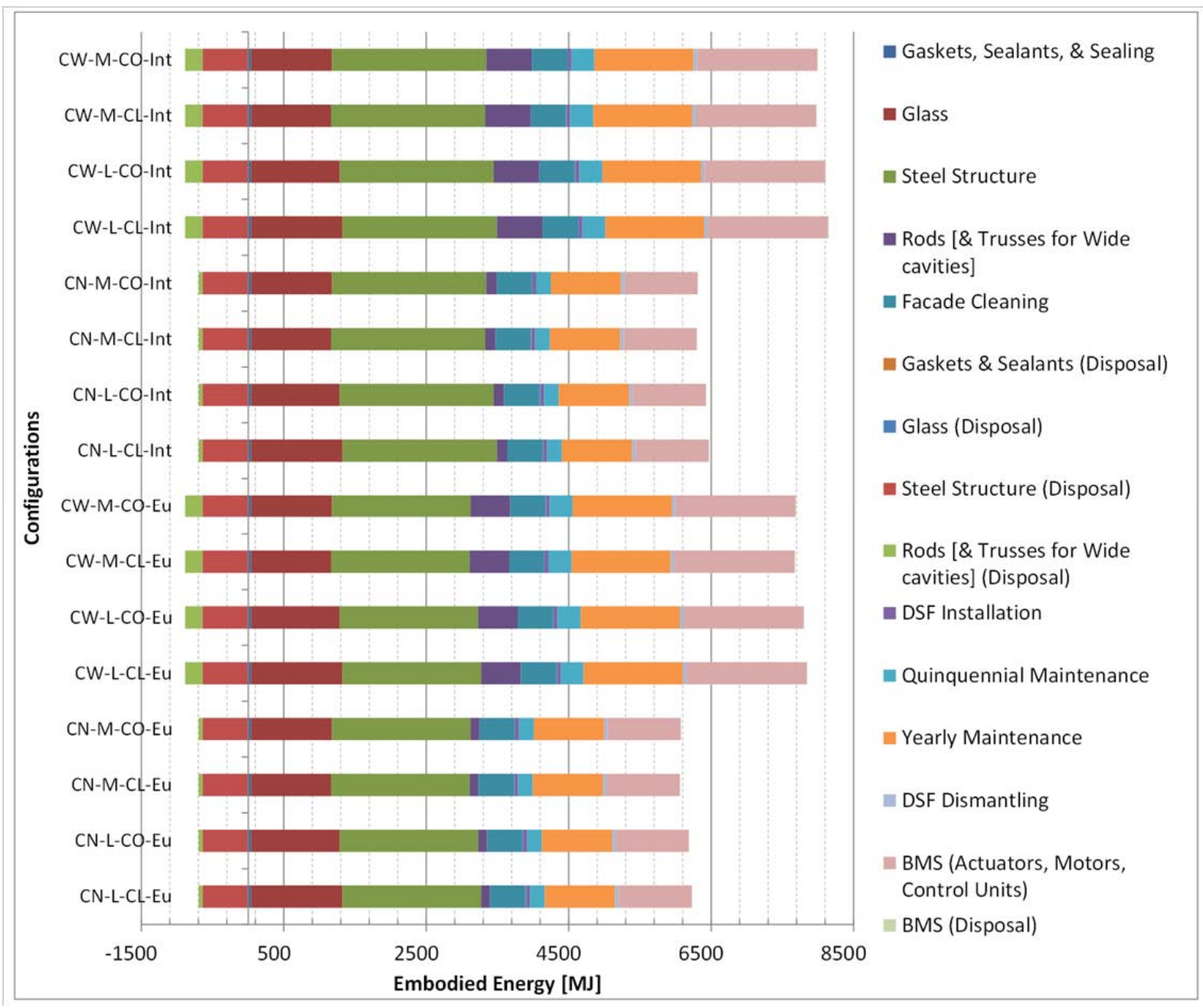

Figure 10 - Embodied Energy for main life cycle stages and assemblies 


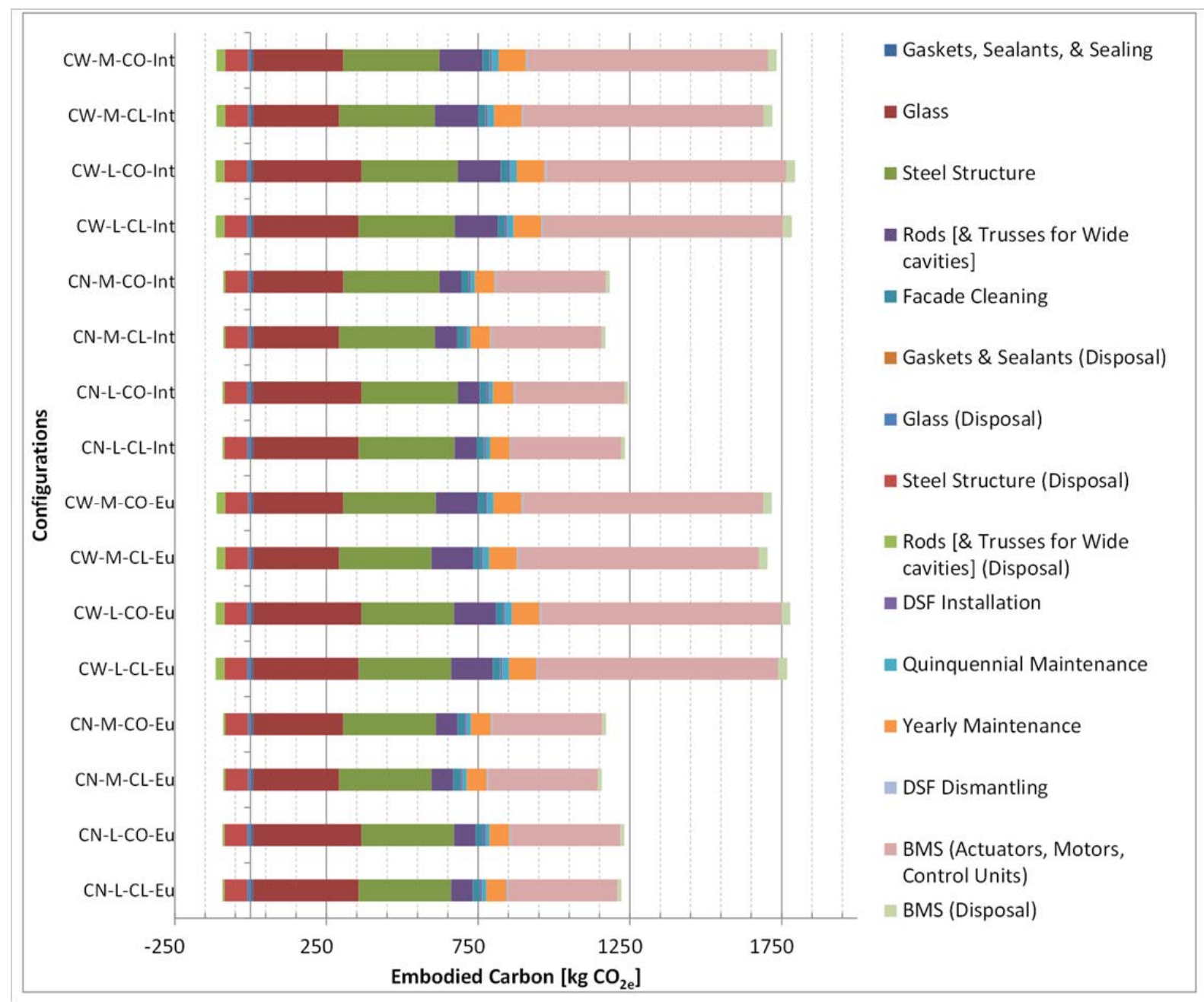

Figure 11 - Embodied carbon for the main life cycle stages and assemblies

Figure 10 also reveals the significant contribution of assemblies and stages that might seem less obvious. Indeed, maintenance activities (assessed according to the façade engineers' recommended schedules), if considered together (both annual and quinquennial), have embodied energy values as high as some of the main macro assemblies of the DSF. These activities mainly involve the need to access the façade to carry out the necessary operations and the use of chemicals and cleaning products for rust removal and stainless steel protection. Equally importantly, the BMS has a major impact on the whole life energy of the DSF. It is note-worthy that the key element that makes the DSF a 'smart' façade and enables it to achieve significant 
operational energy savings is also one that greatly contributes to increasing its embodied impacts.

The impacts related to the BMS and its components (sensors, motors, actuators, etc.) represent an even higher share when the focus switches to carbon (Figure 11) due to the higher carbon density, i.e. how much carbon materials, processes and assembly embody, and also due to the need to replace them over the service life of the façade. The carbon density also increases the significance of glass over steel. Indeed, much of the glass processing happens on electricity-operated machinery and has a higher carbon content that the industrial gas furnaces used in the steel industry.

\subsection{Life Cycle Energy and Carbon Balances}

Figure 12 shows the results for life cycle energy (a) and carbon (b) for the assessed scenarios. Sixteen data series are presented that describe unique combinations of the DSF parameters considered. Each of them includes 8 data points that refer to the different orientations of the building with that specific DSF configuration, thus totalling 128 data points. 


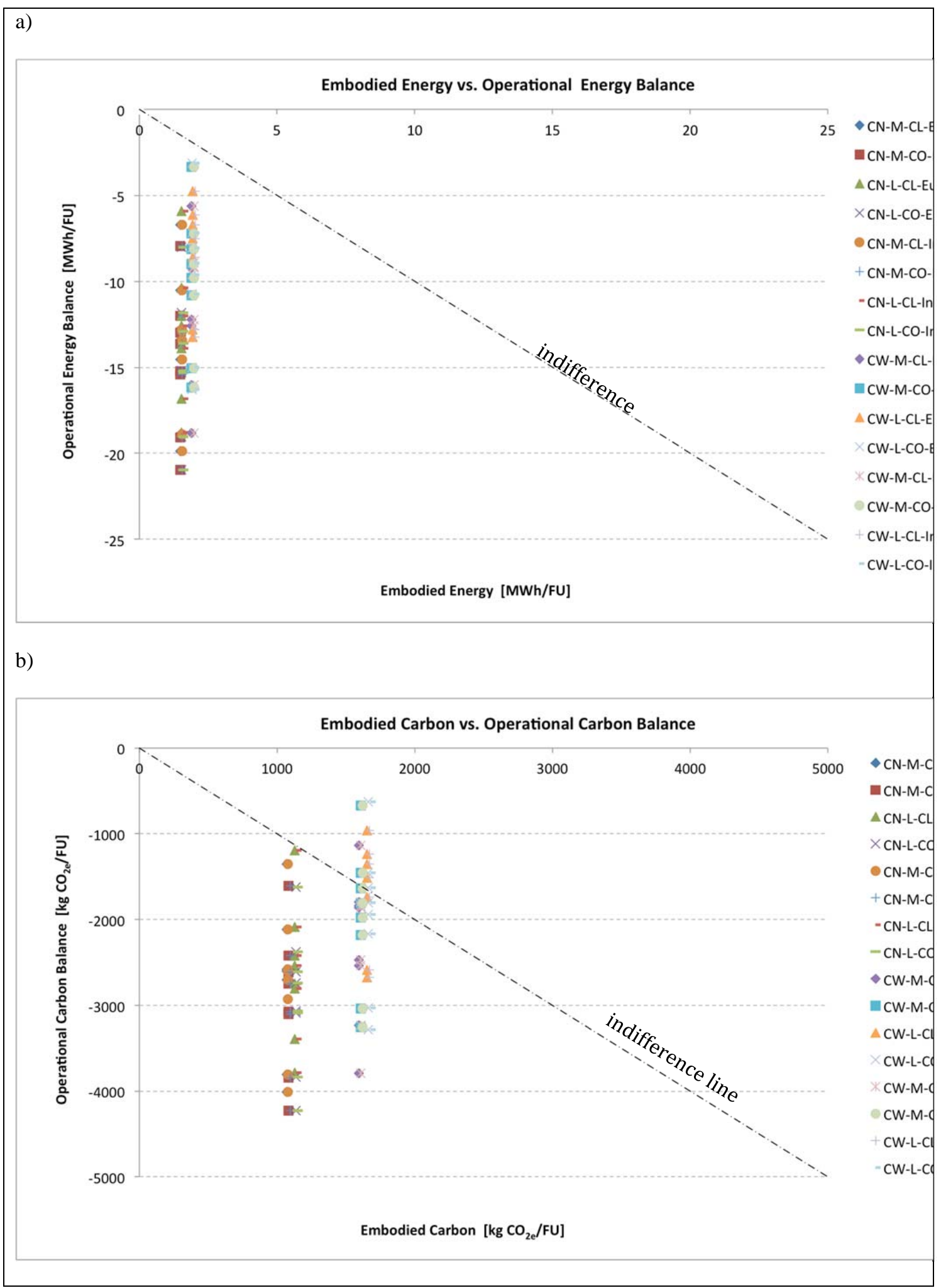

Figure 12 - Embodied Energy vs. Operational Energy balance (a) and Embodied Carbon vs. Operational Carbon balance (b) for the 128 assessed configurations - codes are the same as presented in Table 2

On the $\mathrm{Y}$-axis the operational energy (Figure 12a) and carbon (Figure 12b) savings of DSFs over the equally oriented single-skin alternative are presented. On 
the X-axis the embodied energy (Figure 12a) and carbon (Figure 12b) that DSFs bear over single-skin solutions are plotted. Dashed lines in Figure 12 can be seen as indifference curves: if a point is on the line its embodied energy (carbon) equates to its operational energy (carbon) savings, and therefore there is no difference between that specific DSF configuration and the single skin alternative. Points below those lines represent DSF configurations that are performing better than single-skin and vice versa for the points above. Table 3 shows the exact numerical results for the yearly heating energy (YHE), the life cycle energy and carbon balance for all 128 scenarios, and energy and carbon payback period (PBP) for each of the assessed configurations. PBPs have only been calculated if meaningful, i.e. cases in which the DSF pays back its embodied energy and carbon within the 25 years of its service life. Table 3 also includes operational energy results for the single-skin option in each of the 8 orientations that represented the base case against which operational energy and carbon of DSFs options have been compared.

Energy PBPs range from 1.8 to 6.8 years and from 2.5 to 16.1 years for narrow and wide cavities respectively. Carbon PBPs range from 6.4 to 23.9 years and from 10.5 to 24.8 years for narrow and wide cavities respectively. 
Table 3 - Yearly Heating Energy (YHE) Life Cycle Energy Balance (LCEB), Life Cycle Carbon Balance (LCCB), and energy and carbon payback periods for all the 128 scenarios codes are the same as presented in Table 2

\begin{tabular}{|c|c|c|c|c|c|c|c|c|c|c|c|}
\hline $\begin{array}{l}\text { Narrow Cavities } \\
\text { (codes in Table 2) }\end{array}$ & $\begin{array}{c}\text { YHE } \\
\text { [MWh] }\end{array}$ & $\begin{array}{c}\text { LCEB } \\
\text { [MWh } \\
\text { /FU] }\end{array}$ & $\begin{array}{c}\text { LCCB } \\
{\left[\mathrm{kgCO}_{2 \mathrm{e}} / \mathrm{FU}\right]}\end{array}$ & $\begin{array}{c}\text { Energy } \\
\text { PBP } \\
\text { [years] }\end{array}$ & $\begin{array}{c}\text { Carbon } \\
\text { PBP } \\
\text { [years] }\end{array}$ & $\begin{array}{l}\text { Wide Cavities } \\
\text { (codes in Table 2) }\end{array}$ & $\begin{array}{c}\text { YHE } \\
\text { [MWh] }\end{array}$ & $\begin{array}{c}\text { LCEB } \\
\text { [MWh } \\
\text { /FU] }\end{array}$ & $\begin{array}{c}\text { LCCB } \\
{\left[\mathrm{kgCO}_{2 \mathrm{e}} / \mathrm{FU}\right]}\end{array}$ & $\begin{array}{c}\text { Energy } \\
\text { PBP } \\
\text { [years] }\end{array}$ & $\begin{array}{c}\text { Carbon } \\
\text { PBP } \\
\text { [years] }\end{array}$ \\
\hline CN-M-CL-N-Eu & 735.2 & -11.3 & -1514.9 & 2.9 & 10.3 & CW-M-CL-N-Eu & 788.4 & -7.3 & -266.0 & 5.1 & 21.4 \\
\hline CN-M-CL-NE-Eu & 745.7 & -17.4 & -2743.0 & 2.0 & 7.0 & CW-M-CL-NE-Eu & 788.3 & -14.1 & -1638.8 & 2.9 & 12.3 \\
\hline CN-M-CL-NW-Eu & 657.5 & -11.4 & -1535.2 & 2.9 & 10.3 & CW-M-CL-NW-Eu & 716.6 & -7.0 & -205.4 & 5.3 & 22.1 \\
\hline CN-M-CL-S-Eu & 726.5 & -11.9 & -1633.6 & 2.8 & 9.9 & CW-M-CL-S-Eu & 738.7 & -10.7 & -943.6 & 3.7 & 15.7 \\
\hline CN-M-CL-SE-Eu & 749.2 & -5.2 & -285.6 & 5.6 & 19.7 & CW-M-CL-SE-Eu & 765 & -3.8 & 453.6 & 8.4 & $\mathrm{~N} / \mathrm{A}$ \\
\hline CN-M-CL-SW-Eu & 731.2 & -18.4 & -2940.4 & 1.9 & 6.7 & CW-M-CL-SW-Eu & 747.1 & -16.9 & -2200.2 & 2.5 & 10.5 \\
\hline CN-M-CL-E-Eu & 761.7 & -9.0 & -1050.0 & 3.5 & 12.6 & CW-M-CL-E-Eu & 782.1 & -7.2 & -248.0 & 5.2 & 21.6 \\
\hline CN-M-CL-W-Eu & 702 & -13.1 & -1863.9 & 2.6 & 9.1 & CW-M-CL-W-Eu & 736.1 & -10.4 & -875.2 & 3.9 & 16.1 \\
\hline CN-M-CO-N-Eu & 723.2 & -12.1 & -1664.9 & 2.7 & 9.9 & CW-M-CO-N-Eu & 791.9 & -7.1 & -204.4 & 5.3 & 22.2 \\
\hline CN-M-CO-NE-Eu & 743.3 & -17.6 & -2761.4 & 2.0 & 7.0 & CW-M-CO-NE-Eu & 802.6 & -13.2 & -1429.5 & 3.1 & 13.2 \\
\hline CN-M-CO-NW-Eu & 656.4 & -11.5 & -1535.1 & 2.9 & 10.3 & CW-M-CO-NW-Eu & 728.4 & -6.2 & -30.4 & 5.8 & 24.5 \\
\hline CN-M-CO-S-Eu & 697 & -13.9 & -2021.4 & 2.4 & 8.7 & CW-M-CO-S-Eu & 765 & -8.9 & -571.3 & 4.4 & 18.4 \\
\hline CN-M-CO-SE-Eu & 730.8 & -6.5 & -521.8 & 4.7 & 16.9 & CW-M-CO-SE-Eu & 799.1 & -1.5 & 933.1 & 14.2 & $\mathrm{~N} / \mathrm{A}$ \\
\hline CN-M-CO-SW-Eu & 715.1 & -19.5 & -3146.3 & 1.8 & 6.4 & CW-M-CO-SW-Eu & 786.3 & -14.3 & -1650.9 & 2.9 & 12.3 \\
\hline CN-M-CO-E-Eu & 739.7 & -10.5 & -1336.6 & 3.1 & 11.2 & CW-M-CO-E-Eu & 810.5 & -5.3 & 153.0 & 6.6 & $\mathrm{~N} / \mathrm{A}$ \\
\hline CN-M-CO-W-Eu & 691.6 & -13.8 & -1992.1 & 2.5 & 8.8 & CW-M-CO-W-Eu & 772.1 & -7.9 & -371.0 & 4.8 & 20.3 \\
\hline CN-L-CL-N-Eu & 738.7 & -10.9 & -1406.5 & 3.1 & 11.1 & CW-L-CL-N-Eu & 813.7 & -5.5 & 140.2 & 6.4 & $\mathrm{~N} / \mathrm{A}$ \\
\hline CN-L-CL-NE-Eu & 776.5 & -15.2 & -2262.2 & 2.3 & 8.3 & CW-L-CL-NE-Eu & 829.3 & -11.2 & -1017.9 & 3.6 & 15.5 \\
\hline CN-L-CL-NW-Eu & 671 & -10.4 & -1288.4 & 3.2 & 11.7 & CW-L-CL-NW-Eu & 757.7 & -4.1 & 417.1 & 7.9 & $\mathrm{~N} / \mathrm{A}$ \\
\hline CN-L-CL-S-Eu & 719.1 & -12.3 & -1673.6 & 2.8 & 10.1 & CW-L-CL-S-Eu & 797.4 & -6.6 & -81.9 & 5.6 & 23.8 \\
\hline CN-L-CL-SE-Eu & 760.9 & -4.3 & -64.4 & 6.5 & 23.7 & CW-L-CL-SE-Eu & 848.8 & 2.1 & 1657.5 & $\mathrm{~N} / \mathrm{A}$ & $\mathrm{N} / \mathrm{A}$ \\
\hline CN-L-CL-SW-Eu & 747.7 & -17.1 & -2654.8 & 2.0 & 7.5 & CW-L-CL-SW-Eu & 835.7 & -10.8 & -931.1 & 3.8 & 16.0 \\
\hline CN-L-CL-E-Eu & 763.9 & -8.7 & -958.6 & 3.7 & 13.5 & CW-L-CL-E-Eu & 846.7 & -2.7 & 694.1 & 10.1 & $\mathrm{~N} / \mathrm{A}$ \\
\hline CN-L-CL-W-Eu & 715.8 & -12.0 & -1614.6 & 2.8 & 10.3 & CW-L-CL-W-Eu & 817.9 & -4.7 & 301.8 & 7.2 & $\mathrm{~N} / \mathrm{A}$ \\
\hline
\end{tabular}




\begin{tabular}{|c|c|c|c|c|c|c|c|c|c|c|c|}
\hline $\begin{array}{l}\text { Narrow Cavities } \\
\text { (codes in Table 2) }\end{array}$ & $\begin{array}{c}\text { YHE } \\
{[\mathrm{MWh}]}\end{array}$ & $\begin{array}{c}\text { LCEB } \\
\text { [MWh } \\
\text { /FU] }\end{array}$ & $\begin{array}{c}\mathrm{LCCB} \\
{\left[\mathrm{kgCO}_{2 \mathrm{e}} / \mathrm{FU}\right]} \\
\end{array}$ & $\begin{array}{c}\text { Energy } \\
\text { PBP } \\
\text { [years] }\end{array}$ & $\begin{array}{c}\text { Carbon } \\
\text { PBP } \\
\text { [years] }\end{array}$ & $\begin{array}{l}\text { Wide Cavities } \\
\text { (codes in Table 2) }\end{array}$ & $\begin{array}{c}\mathrm{YHE} \\
{[\mathrm{MWh}]}\end{array}$ & $\begin{array}{c}\text { LCEB } \\
\text { [MWh } \\
\text { /FU] }\end{array}$ & $\begin{array}{c}\mathrm{LCCB} \\
{\left[\mathrm{kgCO}_{2 \mathrm{e}} / \mathrm{FU}\right]}\end{array}$ & $\begin{array}{c}\text { Energy } \\
\text { PBP } \\
\text { [years] }\end{array}$ & $\begin{array}{c}\text { Carbon } \\
\text { PBP } \\
\text { [years] }\end{array}$ \\
\hline CN-L-CO-N-Eu & 723.8 & -12.0 & -1599.7 & 2.8 & 10.4 & CW-L-CO-N-Eu & 792.5 & -6.9 & -138.5 & 5.4 & 23.1 \\
\hline CN-L-CO-NE-Eu & 743.9 & -17.4 & -2696.5 & 2.0 & 7.4 & CW-L-CO-NE-Eu & 803.1 & -13.0 & -1364.5 & 3.2 & 13.7 \\
\hline CN-L-CO-NW-Eu & 657.2 & -11.3 & -1467.3 & 3.0 & 10.9 & CW-L-CO-NW-Eu & 729.2 & -6.0 & 38.2 & 6.0 & $\mathrm{~N} / \mathrm{A}$ \\
\hline CN-L-CO-S-Eu & 698.3 & -13.7 & -1947.1 & 2.5 & 9.2 & CW-L-CO-S-Eu & 765.8 & -8.7 & -502.8 & 4.5 & 19.2 \\
\hline CN-L-CO-SE-Eu & 729.6 & -6.4 & -481.3 & 4.7 & 17.6 & CW-L-CO-SE-Eu & 802.5 & -1.1 & 1036.5 & 15.5 & $\mathrm{~N} / \mathrm{A}$ \\
\hline CN-L-CO-SW-Eu & 715.2 & -19.3 & -3087.1 & 1.8 & 6.7 & CW-L-CO-SW-Eu & 784.3 & -14.3 & -1620.7 & 2.9 & 12.7 \\
\hline CN-L-CO-E-Eu & 742.5 & -10.2 & -1241.0 & 3.2 & 12.0 & CW-L-CO-E-Eu & 810.7 & -5.2 & 212.9 & 6.7 & $\mathrm{~N} / \mathrm{A}$ \\
\hline CN-L-CO-W-Eu & 692.1 & -13.6 & -1927.7 & 2.5 & 9.3 & CW-L-CO-W-Eu & 775 & -7.6 & -272.7 & 5.0 & 21.5 \\
\hline CN-M-CL-N-Int & 735.2 & -11.3 & -1502.4 & 3.0 & 10.5 & CW-M-CL-N-Int & 788.4 & -7.3 & -250.2 & 5.3 & 21.6 \\
\hline CN-M-CL-NE-Int & 745.7 & -17.4 & -2730.6 & 2.1 & 7.1 & CW-M-CL-NE-Int & 788.3 & -14.1 & -1623.0 & 3.1 & 12.4 \\
\hline CN-M-CL-NW-Int & 657.5 & -11.4 & -1522.8 & 3.0 & 10.4 & CW-M-CL-NW-Int & 716.6 & -7.0 & -189.6 & 5.5 & 22.4 \\
\hline CN-M-CL-S-Int & 726.5 & -11.9 & -1621.2 & 2.9 & 10.0 & CW-M-CL-S-Int & 738.7 & -10.6 & -927.9 & 3.9 & 15.9 \\
\hline CN-M-CL-SE-Int & 749.2 & -5.2 & -273.2 & 5.8 & 20.0 & CW-M-CL-SE-Int & 765 & -3.7 & 469.3 & 8.7 & $\mathrm{~N} / \mathrm{A}$ \\
\hline CN-M-CL-SW-Int & 731.2 & -18.3 & -2928.0 & 2.0 & 6.7 & CW-M-CL-SW-Int & 747.1 & -16.8 & -2184.4 & 2.6 & 10.6 \\
\hline CN-M-CL-E-Int & 761.7 & -9.0 & -1037.6 & 3.7 & 12.7 & CW-M-CL-E-Int & 782.1 & -7.2 & -232.2 & 5.4 & 21.8 \\
\hline CN-M-CL-W-Int & 702 & -13.0 & -1851.4 & 2.7 & 9.2 & CW-M-CL-W-Int & 736.1 & -10.3 & -859.4 & 4.0 & 16.3 \\
\hline CN-M-CO-N-Int & 723.2 & -12.1 & -1652.5 & 2.9 & 10.0 & CW-M-CO-N-Int & 791.9 & -7.0 & -188.6 & 5.5 & 22.4 \\
\hline CN-M-CO-NE-Int & 743.3 & -17.5 & -2749.0 & 2.0 & 7.1 & CW-M-CO-NE-Int & 802.6 & -13.1 & -1413.7 & 3.3 & 13.4 \\
\hline CN-M-CO-NW-Int & 656.4 & -11.4 & -1522.7 & 3.0 & 10.5 & CW-M-CO-NW-Int & 728.4 & -6.1 & -14.6 & 6.1 & 24.8 \\
\hline CN-M-CO-S-Int & 697 & -13.8 & -2009.0 & 2.5 & 8.8 & CW-M-CO-S-Int & 765 & -8.8 & -555.5 & 4.6 & 18.6 \\
\hline CN-M-CO-SE-Int & 730.8 & -6.4 & -509.4 & 4.9 & 17.1 & CW-M-CO-SE-Int & 799.1 & -1.4 & 948.9 & 14.8 & $\mathrm{~N} / \mathrm{A}$ \\
\hline CN-M-CO-SW-Int & 715.1 & -19.4 & -3133.9 & 1.9 & 6.5 & CW-M-CO-SW-Int & 786.3 & -14.2 & -1635.1 & 3.1 & 12.4 \\
\hline CN-M-CO-E-Int & 739.7 & -10.4 & -1324.2 & 3.3 & 11.3 & CW-M-CO-E-Int & 810.5 & -5.2 & 168.7 & 6.8 & $\mathrm{~N} / \mathrm{A}$ \\
\hline CN-M-CO-W-Int & 691.6 & -13.7 & -1979.7 & 2.6 & 8.9 & CW-M-CO-W-Int & 772.1 & -7.8 & -355.2 & 5.0 & 20.5 \\
\hline CN-L-CL-N-Int & 738.7 & -10.9 & -1394.1 & 3.2 & 11.3 & CW-L-CL-N-Int & 813.7 & -5.4 & 156.0 & 6.7 & $\mathrm{~N} / \mathrm{A}$ \\
\hline CN-L-CL-NE-Int & 776.5 & -15.1 & -2249.8 & 2.4 & 8.4 & CW-L-CL-NE-Int & 829.3 & -11.1 & -1002.1 & 3.8 & 15.6 \\
\hline
\end{tabular}




\begin{tabular}{|c|c|c|c|c|c|c|c|c|c|c|c|}
\hline $\begin{array}{l}\text { Narrow Cavities } \\
\text { (codes in Table 2) }\end{array}$ & $\begin{array}{c}\text { YHE } \\
\text { [MWh] }\end{array}$ & $\begin{array}{c}\text { LCEB } \\
\text { [MWh } \\
\text { /FU] } \\
\end{array}$ & $\begin{array}{c}\mathrm{LCCB} \\
{\left[\mathrm{kgCO}_{2 \mathrm{e}} / \mathrm{FU}\right]} \\
\end{array}$ & $\begin{array}{c}\text { Energy } \\
\text { PBP } \\
\text { [years] } \\
\end{array}$ & $\begin{array}{c}\text { Carbon } \\
\text { PBP } \\
\text { [years] } \\
\end{array}$ & $\begin{array}{c}\text { Wide Cavities } \\
\text { (codes in Table 2) }\end{array}$ & $\begin{array}{c}\text { YHE } \\
\text { [MWh] }\end{array}$ & $\begin{array}{c}\text { LCEB } \\
\text { [MWh } \\
\text { /FU] } \\
\end{array}$ & $\begin{array}{c}\text { LCCB } \\
{\left[\mathrm{kgCO}_{2 \mathrm{e}} / \mathrm{FU}\right]}\end{array}$ & $\begin{array}{c}\text { Energy } \\
\text { PBP } \\
\text { [years] } \\
\end{array}$ & $\begin{array}{c}\text { Carbon } \\
\text { PBP } \\
\text { [years] }\end{array}$ \\
\hline CN-L-CL-NW-Int & 671 & -10.3 & -1275.9 & 3.3 & 11.8 & CW-L-CL-NW-Int & 757.7 & -4.0 & 432.9 & 8.2 & N/A \\
\hline CN-L-CL-S-Int & 719.1 & -12.2 & -1661.2 & 2.9 & 10.2 & CW-L-CL-S-Int & 797.4 & -6.5 & -66.2 & 5.9 & 24.0 \\
\hline CN-L-CL-SE-Int & 760.9 & -4.2 & -51.9 & 6.8 & 23.9 & CW-L-CL-SE-Int & 848.8 & 2.1 & 1673.3 & N/A & N/A \\
\hline CN-L-CL-SW-Int & 747.7 & -17.1 & -2642.4 & 2.1 & 7.5 & CW-L-CL-SW-Int & 835.7 & -10.7 & -915.3 & 3.9 & 16.2 \\
\hline CN-L-CL-E-Int & 763.9 & -8.7 & -946.2 & 3.9 & 13.7 & CW-L-CL-E-Int & 846.7 & -2.6 & 709.9 & 10.6 & N/A \\
\hline CN-L-CL-W-Int & 715.8 & -11.9 & -1602.2 & 2.9 & 10.4 & CW-L-CL-W-Int & 817.9 & -4.6 & 317.6 & 7.5 & N/A \\
\hline CN-L-CO-N-Int & 723.8 & -11.9 & -1587.3 & 2.9 & 10.5 & CW-L-CO-N-Int & 792.5 & -6.8 & -122.8 & 5.6 & 23.3 \\
\hline CN-L-CO-NE-Int & 743.9 & -17.3 & -2684.1 & 2.1 & 7.5 & CW-L-CO-NE-Int & 803.1 & -12.9 & -1348.7 & 3.3 & 13.9 \\
\hline CN-L-CO-NW-Int & 657.2 & -11.2 & -1454.9 & 3.1 & 11.1 & CW-L-CO-NW-Int & 729.2 & -6.0 & 54.0 & 6.2 & N/A \\
\hline CN-L-CO-S-Int & 698.3 & -13.6 & -1934.7 & 2.6 & 9.3 & CW-L-CO-S-Int & 765.8 & -8.6 & -487.0 & 4.7 & 19.4 \\
\hline CN-L-CO-SE-Int & 729.6 & -6.3 & -468.9 & 5.0 & 17.8 & CW-L-CO-SE-Int & 802.5 & -1.0 & 1052.3 & 16.1 & N/A \\
\hline CN-L-CO-SW-Int & 715.2 & -19.3 & -3074.7 & 1.9 & 6.8 & CW-L-CO-SW-Int & 784.3 & -14.2 & -1604.9 & 3.1 & 12.8 \\
\hline CN-L-CO-E-Int & 742.5 & -10.1 & -1228.6 & 3.4 & 12.1 & CW-L-CO-E-Int & 810.7 & -5.1 & 228.7 & 7.0 & N/A \\
\hline CN-L-CO-W-Int & 692.1 & -13.5 & -1915.2 & 2.6 & 9.4 & CW-L-CO-W-Int & 775 & -7.5 & -257.0 & 5.2 & 21.7 \\
\hline Code & $\begin{array}{c}\text { YHE } \\
\text { [MWh] }\end{array}$ & & & & & Code & $\begin{array}{c}\text { YHE } \\
\text { [MWh] }\end{array}$ & & & & \\
\hline single-skin-N & 924.8 & $\mathrm{~N} / \mathrm{A}^{*}$ & $\mathrm{~N} / \mathrm{A}^{*}$ & / & / & single-skin-E & 917.2 & $\mathrm{~N} / \mathrm{A}^{*}$ & $\mathrm{~N} / \mathrm{A}^{*}$ & / & / \\
\hline single-skin-NE & 1025.4 & N/A* & N/A* & / & / & single-skin-S & 924.8 & N/A* & N/A* & / & / \\
\hline single-skin-NW & 848.5 & $\mathrm{~N} / \mathrm{A}^{*}$ & N/A* & / & / & single-skin-SE & 848.5 & $N / A^{*}$ & N/A* & / & / \\
\hline single-skin-W & 917.2 & N/A* & N/A* & / & I & single-skin-SW & 1025.4 & N/A* & N/A* & / & / \\
\hline
\end{tabular}

*: Not Applicable since the single-skin options (one for each orientation) are the base cases against which the DSF performance difference has been compared 
Figure 12a highlights the energy saving potential of the DSF. $98.4 \%$ of the scenarios assessed (126 out of 128) outperform the single-skin alternative from an energy point of view over their life cycle. Negative signs in Table 2 represent the amount of energy (carbon) saved by that specific DSF configuration over the equally-oriented single-skin alternative from a whole-life perspective. The two DSF configurations which are outperformed by the singleskin alternative from a life cycle energy point of view can be seen in the two red cells of the LCEB columns of Table 3. Both cases refer to scenarios where the DSF has a wide cavity, a laminated clear glass, and is SE oriented.

By looking more closely at Figure 12a and Table 3 it is possible to note that in those two cases the DSF operational energy savings are null. In fact, as Table 3 shows, the use of a DSF actually increases the yearly heating load by 0.3 MWh. This is due to the specific orientation and configuration of those options. In fact, a SE oriented building can benefit from a fair amount of solar gain therefore the SE oriented single skin model is the one with the least energy consumption amongst the eight single skin options.

In terms of embodied energy, Figure 12a shows that the variations of EE related to the parameters considered are negligible if compared to the variation of operational energy savings related to the 8 different orientations considered. Very few options are near to the indifference line (this can be seen numerically in the LCEB columns of Table 3); which allows for some confidence in supporting the choice of DSFs over the single-skin alternative from a life-cycle energy perspective.

Results change when the focus switches from energy to carbon. The number of DSF configurations which are outperformed by the single-skin alternative over their life cycle increases from 2 to 22. This is due to the different carbon density that assemblies and stages have and highlight a major shortcoming of solely focusing on embodied energy, i.e. the lack of consideration of the carbon density of the energy carrier. For instance, 1GJ of coal causes 
the emission of $15.39 \mathrm{kgCO}_{2 \mathrm{e}}$ whereas $1 \mathrm{GJ}$ of natural gas produces $5.55 \mathrm{kgCO}_{2 \mathrm{e}}$ [61]. From the energy point of view, both represent 1GJ obtained from non-renewable, fossil elements and therefore the energy analysis would not distinguish between the two despite the carbon density of coal is almost three times as much that of natural gas.

The parametric approach adopted in this study allows for some significant insights. By looking at Figure 12b it can be seen that the cavity width is the parameter that makes the most difference from EE to EC. It must be noted that all the DSF options with adverse effects on either life cycle energy or carbon balance have a wide cavity. Therefore, the cavity width seems to be the only and true discriminant between successful and counterproductive DSF installations, where a successful DSF configuration is one that saves energy and carbon over its life cycle compared to a single-skin alternative. The reason why wide cavities are less energy and carbon efficient is twofold. Firstly, wide cavities require a higher amount of construction materials thus presenting higher values of embodied energy and embodied carbon. Secondly, wide cavities have openings 2.5 times bigger than narrow ones, thus creating a higher volume and consequently a higher mass of air that needs to be warmed up before it starts acting effectively as a thermal buffer. Additionally, because the cavity opens when the inside air reaches the threshold temperature, a larger amount of cold air from outside enters.

Orientation, glass type and glass coating, in such order, follow in terms of significance, with monolithic glass to be preferred over laminated glass. Transportation ormore exactly - the source of materials for the structural system is the least impacting parameter, however EU-sourced materials show lower impacts than those coming from China.

With respect to glass choice, each of the combination groups (M-CL, M-CO, L-CL, L-CO) have one or more adverse options in terms of embodied carbon (Table 3). Such a 
pattern impedes further grouping the configurations that should be adopted according to glass characteristics other than the preference of monolithic over laminated glass, as already explained. Orientation does not help either; the options with adverse effects belong to various orientations although South-related orientations seem more prone to being energy and carbon efficient than North-related ones when compared to the single skin alternative. This can be understood as a DSF installed on the South (or South-East/West) side of a building receives a large amount of solar radiation, which promotes both the stack effect and the thermal buffer behaviour of the DSF. Nonetheless, even in terms of life cycle carbon balance, nearly $83 \%$ of the assessed options (106 out of 128) outperform the single-skin alternative and reduce the total $\mathrm{CO}_{2 \mathrm{e}}$ emissions over the whole life cycle.

\section{Conclusions}

This paper investigated the use of DSF with a stainless steel structural system in the refurbishment of existing office buildings in the UK. With respect to the research questions that this study aims to answer, results have shown that for the vast majority of the options assessed DSFs perform extremely well when looked at from a life cycle perspective. More specifically, a comparative cradle-to-grave life cycle assessment study was conducted to analyse DSF refurbishment strategies against an up-to-standard single skin alternative. Cavity width, glass composition and glass coating, source of construction materials, and orientations of the building are all elements that drove this parametric study, which considered a total of 128 DSF configurations. Embodied energy (in $\mathrm{MWh} / \mathrm{FU}$ ) and embodied carbon (in $\mathrm{kg}$ $\mathrm{CO}_{2 \mathrm{e}} / \mathrm{FU}$ ) are the units assessed throughout the study to determine the whole life energy and carbon figures when combined with the operational energy and carbon balances over the 25 years of the façade service life. 98\% of the DSF configurations have a better life cycle energy performance than the single skin alternative and nearly $83 \%$ a better life cycle carbon performance. In terms of cavity width, all options with a narrow cavity performed better than 
the single-skin alternative whereas some of those with a wide cavity did not. Findings from this study strongly indicate the DSF as a successful means to reduce the life cycle energy consumption of existing buildings as well as a low-carbon technology for their sustainable refurbishment.

However, those options that had an adverse effect on the life cycle balances highlight the need for an extremely careful DSF design. In fact, in some cases, a simple difference of $45^{\circ}$ in the orientation of the building has been the element of variation that shifted the DSF from outperforming the single-skin alternative to being outperformed by it, due to the significant role played by operational energy consumption. This study has also provided valuable insights on (1) the distribution of overall embodied energy and carbon within the different life cycle stages, processes, and assemblies involved in and necessary to a DSF refurbishment, and on (2) the operational energy consumption in terms of space heating load of a significant number of DSF configurations.

This research has represented a first attempt to shed light on the life cycle impacts of commonly used DSF configurations in the AEC sector. The two units assessed highlighted that results differ when the focus switches from energy consumption to carbon emissions, and several energy-efficient configurations from a life cycle perspective are not equally carbonefficient. Such a peculiarity calls for a more holistic approach in evaluating life cycle impacts. Embodied energy, in fact, cannot account for the carbon density of the energy carrier (e.g. coal vs. natural gas) and, therefore, it should be coupled with embodied carbon if truly environmentally conscious decisions are to be made.

It should be noted that the use of DSF in refurbishments requires extra space around the existing building, and for offices in very central built up areas such space might not be available. The focus on a specific climate, i.e. London, and a specific structure, i.e. stainless steel, in addition to the uncertainty of the database used and the lack of uncertainty analysis 
of the data collected (through, for instance, Monte Carlo simulation) can all be seen as limitations of this study and represent important and interesting areas for further research. Future research could also use assessment methods that look at a broader range of impact categories to determine whether the great potential that DSFs seem capable of offering holds true under a variety of alternatives and also in different contexts.

\section{References}

[1] DCLG, Improving the energy efficiency of buildings and using planning to protect the environment, Edited by Department for Communities and Local Government. First Published 7th November 2012 - Last Updated 16th April 2014 - Her Majesty Government, London, 2012.

[2] L. Thomas, Evaluating design strategies, performance and occupant satisfaction: a low carbon office refurbishment, Building Research \& Information: The International Journal of Research, Development and Demonstration, 38 (6) (2010) 610-624.

[3] CIBSE, BSRIA, Refurbishment for Improved Energy Efficiency: An Overview, CIBSE (Ed.) Knowledge Series 12, 2007, pp. 48.

[4] Carbon Trust, Building the future, today. Transforming the economic and carbon performance of the buildings we work in, 2009.

[5] IEA, Technology Roadmap. Energy efficient building envelopes, International Energy Agency, Paris, France, 2014.

[6] L. Pérez-Lombard, J. Ortiz, C. Pout, A review on buildings energy consumption information, Energy and Buildings, 40 (3) (2008) 394-398.

[7] F. Stevenson, Reducing energy demand through retrofitting buildings, Building Research \& Information, 41 (5) (2013) 605-608.

[8] CIBSE, CIBSE TM 53: 2013 - Refurbishment of non-domestic buildings, Chartered Institution of Building Services Engineers - Great Britain, 2013.

[9] F. Pomponi, E.R.P. Farr, P. Piroozfar, J.R. Gates, Façade refurbishment of existing office buildings: Do conventional energy-saving interventions always work?, Journal of Building Engineering, 3 (2015) 135-143.

[10] LCICG, Low Carbon Innovation Coordination Group. Non-Domestic Buildings Summary Report, in, Department of Energy and Climate Change \& Carbon Trust, UK, 2012. [11] J. Ferreira, M.D. Pinheiro, J.d. Brito, Refurbishment decision support tools reviewEnergy and life cycle as key aspects to sustainable refurbishment projects, Energy Policy, 62 (2013) 1453-1460.

[12] A. Aksamija, Sustainable Facades: Design Methods for High-performance Building Envelopes, John Wiley \& Sons, 2013.

[13] Y. Kaluarachchi, A.K. Jones, P. James, M. Jentsch, A.S. Baha, D. Clements-Croome, D. Gann, Building facades: sustainability, maintenance and refurbishment, Engineering Sustainability, Proceedings of the Institution of Civil Engineers, 2005, pp. 89-95.

[14] M.A. Shameri, M.A. Alghoul, K. Sopian, M.F.M. Zain, O. Elayeb, Perspectives of double skin facade systems in buildings and energy saving, Renewable \& Sustainable Energy Reviews, 15 (3) (2011) 1468-1475.

[15] I. Cetiner, E. Ozkan, An approach for the evaluation of energy and cost efficiency of glass facades, Energy and Buildings, 37 (6) (2005). 
[16] S. Brunoro, An assessment of energetic efficiency improvement of existing building envelopes in Italy, Management of Environmental Quality: An International Journal, 19 (6) (2008) 718-730.

[17] I. Perez-Grande, J. Meseguer, G. Alonso, Influence of glass properties on the performance of double-glazed facades, Applied Thermal Engineering, 25 (17-18) (2005).

[18] E. Gratia, A. De Herde, Are energy consumptions decreased with the addition of a double-skin?, Energy and Buildings, 39 (5) (2007).

[19] N. Papadaki, S. Papantoniou, D. Kolokotsa, A parametric study of the energy performance of double-skin façades in climatic conditions of Crete, Greece, International Journal of Low-Carbon Technologies, (2013).

[20] N. Hamza, M. Cook, P. Cropper, Comparative Analysis of Natural Ventilation Performance in Non-Uniform Double Skin Facades in Temperate Climates, in: Proceedings of Building Simulation 2011 -12th Conference of International Building Performance Simulation Association, Sydney, 14-16 November, 2011, pp. 2401-2406.

[21] T. Pasquay, Natural ventilation in high-rise buildings with double facades, saving or waste of energy, Energy and Buildings, 36 (4) (2004) 381-389.

[22] N. Artmann, T. Sattelmayer, M. Spinnler, Double-Skin Facades with Diverse Sunscreen Configuration, in, International Symposium on the Application of Architectural Glass, 2004.

[23] A.M. Moncaster, J.Y. Song, A comparative review of existing data and methodologies for calculating embodied energy and carbon of buildings, International Journal of Sustainable Building Technology and Urban Development, 3 (1) (2012) 26-36.

[24] ISO, BSI EN ISO 14040:2006 Environmental management - life cycle assessment principles and framwork, in, British Standard Institution, United Kingdom, 2006.

[25] ISO, BSI EN ISO 14044:2006 Environmental management - life cycle assessment requirement and guidelines, 2006.

[26] BS, BS EN 15643-1:2010 Sustainability of contruction works - Sustainability assessment of buildings. Part 1: General framework, 2010.

[27] BS, BS EN 15643-2:2011. Sustainability of construction works — Sustainability assessment of buildings. Part 2: Framework for the assessment of environmental performance, 2011.

[28] L.F. Cabeza, L. Rincón, V. Vilariño, G. Pérez, A. Castell, Life cycle assessment (LCA) and life cycle energy analysis (LCEA) of buildings and the building sector: A review, Renewable and Sustainable Energy Reviews, 29 (0) (2014) 394-416.

[29] M. Erlandsson, M. Borg, Generic LCA-methodology applicable for buildings, constructions and operation services-today practice and development needs, Building and Environment, 38 (7) (2003) 919-938.

[30] W. Collinge, A. Landis, A. Jones, L. Schaefer, M. Bilec, Dynamic life cycle assessment: framework and application to an institutional building, The International Journal of Life Cycle Assessment, 18 (3) (2013) 538-552.

[31] M.K. Dixit, J.L. Fernandez-Solis, S. Lavy, C.H. Culp, Need for an embodied energy measurement protocol for buildings: A review paper, Renewable \& Sustainable Energy Reviews, 16 (6) (2012) 3730-3743.

[32] M. Buyle, J. Braet, A. Audenaert, Life cycle assessment in the construction sector: A review, Renewable and Sustainable Energy Reviews, 26 (0) (2013) 379-388.

[33] G. Wadel, P. Alonso, J.-L. Zamora, P. Garrido, Simplified LCA in skin design: The FB720 case, International Journal of Sustainable Building Technology and Urban Development, 4 (1) (2013) 68-81.

[34] A. de Gracia, L. Navarro, A. Castell, D. Boer, L.F. Cabeza, Life cycle assessment of a ventilated facade with PCM in its air chamber, Solar Energy, (0) (2013). 
[35] PRé-Consultants, The Eco-Indicator 99. A damage oriented method for lice cycle impact assessment. Methodology report and manual for designers. Technical Report, PRéConsultants, Amersfoort. The Netherlands, 2000.

[36] M. Kolokotroni, S. Robinson-Gayle, S. Tanno, A. Cripps, Environmental impact analysis for typical office facades, Building Research \& Information, 32 (1) (2004) 2-16.

[37] E.C. Peereboom, R. Kleijn, S. Lemkowitz, S. Lundie, Influence of Inventory Data Sets on Life-Cycle Assessment Results: A Case Study on PVC, Journal of Industrial Ecology, 2 (3) (1998) 109-130.

[38] J. Reap, F. Roman, S. Duncan, B. Bras, A survey of unresolved problems in life cycle assessment, The International Journal of Life Cycle Assessment, 13 (5) (2008) 374-388.

[39] R.H. Crawford, Life cycle energy and greenhouse emissions analysis of wind turbines and the effect of size on energy yield, Renewable and Sustainable Energy Reviews, 13 (9) (2009) 2653-2660.

[40] BSI, PAS 2050:2011. Specification for the assessment of the life cycle greenhouse gas emissions of goods and services, 2011.

[41] M. Shahrestani, R. Yao, G.K. Cook, A review of existing building benchmarks and the development of a set of reference office buildings for England and Wales, Intelligent Buildings International, 6 (1) (2013) 41-64.

[42] P. Steadman, H.R. Bruhns, S. Holtier, B. Gakovic, P.A. Rickaby, F.E. Brown, A classification of built forms, Environment and Planning B: Planning and Design, 27 (1) (2000) 73-91.

[43] B. Gakovic, Areas and types of glazing and other openings in the nondomestic building stock, Environment and Planning B: Planning and Design, 27 (2000) 667-694.

[44] ODPM, Age of Commercial and Insustrial Stock: Local Authority Level 2004, Office of the Deputy Prime Minister, ODPM Publications - Crown copyright 2005, London, 2005, pp. 24.

[45] S. Barlow, D. Fiala, Occupant comfort in UK offices-How adaptive comfort theories might influence future low energy office refurbishment strategies, Energy and Buildings, 39 (7) (2007) 837-846.

[46] Q. Jin, M. Overend, A prototype whole-life value optimization tool for façade design, Journal of Building Performance Simulation, (2013) 1-16.

[47] B.P. Weidema, C. Bauer, R. Hischier, C. Mutel, T. Nemecek, J. Reinhard, C.O. Vadenbo, G. Wernet, The ecoinvent database: Overview and methodology, Data quality guideline for the ecoinvent database version 3, www.ecoinvent.org, 2013.

[48] R.H. Crawford, Life Cycle Assessment in the Built Environment, Spon Press, London, New York, 2011.

[49] G.P. Hammond, C.I. Jones, Embodied energy and carbon in construction materials, Proceedings of the ICE - Energy, 2008, pp. 87-98.

[50] R. Frischknecht, N. Jungbluth, e. al., Implementation of Life Cycle Impact Assessment Methods. Final report ecoinvent 2000, Swiss Centre for LCI. , Duebendorf, CH, 2003. [51] IPCC, Intergovernmental Panel on Climate Change. Working Group I Contribution to the Fifth Assessment Report of the Intergovernmental Panel on Climate Change. Climate Change 2013 - The Physical Science Basis, in [Stocker, T.F., D. Qin, G.-K. Plattner, M. Tignor, S.K. Allen, J. Boschung, A. Nauels, Y. Xia, V. Bex and P.M. Midgley (eds.)], Cambridge University Press, Cambridge, United Kingdom and New York, NY, USA, 1535 pp., 2013.

[52] IES, Building Energy and Environmental Modelling; Checklist for Choosing BEEM Software. ApacheSim., 2009.

[53] IES, MacroFlo Calculation Methods. Technical Manual., 2014. 
[54] M.C. Peel, B.L. Finlayson, T.A. McMahon, Updated world map of the Köppen-Geiger climate classification, Hydrology and earth system sciences discussions, 4 (2) (2007) 439473.

[55] BSI, BS EN 13119:2007. Curtain walling. Terminology, British Standard Institution 2007.

[56] DCLG, The Building Regulation 2010 edition. Approved Document L2B. Conservation of fuel and power in existing buildings other than dwellings., UK Government, London, 2010.

[57] G. Hammond, C. Jones, Embodied carbon: the inventory of carbon and energy (ICE). BG 10/2011, University of Bath and BSRIA, 2011.

[58] B.P. Weidema, C. Bauer, R. Hischier, C. Mutel, T. Nemecek, J. Reinhard, C.O. Vadenbo, G. Wernet, Overview and methodology. Data quality guideline for the EcoInvent database Version 3. Ecoinvent Report 1(v3). Swiss Centre for Life Cycle Inventories., St. Gallen: The ecoinvent centre, 2013.

[59] CIBSE, CIBSE TM 46: 2008 - Energy benchmarks, Chartered Institution of Building Services Engineers - Great Britain, 2008.

[60] CIBSE, CIBSE Guide F. Energy efficiency in buildings., Chartered Institution of Building Services Engineers - Great Britain, 2012.

[61] N. Hill, H. Walker, J. Beevor, K. James, Guidelines to Defra / DECC’s GHG Conversion Factors for Company Reporting: Methodology Paper for Emission Factors, DEFRA, Department for Environment, Food and Rural Affairs (DEFRA) and Department of Energy and Climate Change (DECC). London, 2011.

\section{Acknowledgements}

The authors would like to acknowledge the insightful comments received from one of the reviewers which helped improve the quality of the article significantly. They are also extremely grateful to Mr Rhys Trussler for proofreading the manuscript. 